\title{
Large Magnetic Anisotropy in Mononuclear Metal Complexes
}

\author{
Silvia Gómez-Coca, Daniel Aravena, Roser Morales, Eliseo Ruiz* \\ Departament de Química Inorgànica and Institut de Recerca de Química Teòrica i Computacional, \\ Universitat de Barcelona, Diagonal 645, E-08028 Barcelona, Spain \\ e-mail eliseo.ruiz@qi.ub.es
}

\author{
Contents \\ 1. Introduction \\ 2. Mononuclear Single-Molecule Magnets \\ 3. Rationalization of the Magnetic Anisotropy of Mononuclear Transition Metal SMM \\ 4. Rationalization of the Magnetic Anisotropy of Mononuclear Lanthanide SMM \\ 5. Concluding remarks
}

\begin{abstract}
This review examines mononuclear metal complexes with high magnetic anisotropy and the theoretical approaches used to rationalize their magnetic properties. Electronic structure calculations based on CASSCF (or CASPT2/NEVPT2) methods provide a quantitative agreement of the zerofield splitting parameters either for mononuclear transition metal complexes or for equivalent lanthanide systems. To produce a more qualitative tool for predicting the magnetic anisotropy of metal complexes, we have developed a set of simple models. For transition metal systems, a simple model based on the splitting of the $d$ orbitals, considering the coordination mode of the metal and its electronic configuration, is enough to qualitatively predict the system's magnetic anisotropy. A similar approach does not work with the $f$ orbitals of the lanthanide complexes. As an alternative, we studied the electrostatic field generated by the ligands and found that this magnitude controls the shape and the orientation of the anisotropic electron density. This procedure allows us to rationalize and to predict whether the system will have a strong axial character, and also to determine the direction of the magnetic moment.
\end{abstract}

Keywords: Magnetic Anisotropy, ab initio Calculations, Single-Molecule Magnets, Molecular Magnetism 


\section{Introduction}

Magnetic anisotropy is the property that confers a preferred direction on the spin of a system which may not be aligned with an external magnetic field, as promoted by the Zeeman effect. If there is a preferred direction, the systems are usually classified as easy axis; however, if the spin remains confined in a plane, the systems are called easy plane.[1] Therefore, molecules that show a high degree of magnetic anisotropy can behave as individual nanomagnets in the absence of a magnetic field, due to the predisposition to keep their inherent spin direction.[2-4] During recent decades, synthetic chemists have made considerable efforts to produce new transition metal complexes able to behave as small nanomagnets (single-molecule magnets, SMMs).[5, 6] As magnetic anisotropy is very hard to predict and control, most of the complexes with large magnetic anisotropy have been obtained through serendipitous processes. In this way, many polynuclear transition metal complexes which showed slow relaxation of their magnetization have been synthesized. This relaxation is essentially controlled by an energy barrier that may fix the spin direction.[2,3] The usual spin Hamiltonian for dealing with such effects include the zero-field splitting (ZFS) terms[7, 8] that involve magnetic anisotropy:

$$
\hat{H}=D\left(\hat{S}_{z}^{2}-\frac{1}{3} \hat{S}^{2}\right)+E\left(\hat{S}_{x}^{2}-\hat{S}_{y}^{2}\right)
$$

where D and E is the axial and rhombic ZFS parameters and $\hat{S}\left(\hat{S}_{i}\right)$ is the total spin moment (and its components) of the molecule. In relation to the anisotropy of the system, a negative $\mathrm{D}$ value corresponds to an easy axis system while a positive one results in an easy plane system. The height of the magnetic anisotropy barrier depends on the total spin of the system and is given by the product $|\mathrm{D}| \cdot \mathrm{S}^{2}$ for integer spins and $|\mathrm{D}| \cdot \mathrm{S}^{2}-1 / 4$ for half-integer spins. The spin direction may be flipped (in the relaxation process) due to thermal crossing of the energy barrier or tunneling effects (thermal-assisted or in ground state) usually quantified by E, the rhombic ZFS parameter. SMM behavior has usually been characterized by two specific "fingerprints", which have been well described in the past: opening of a hysteresis loop with the presence of steps due to tunneling effects and frequency dependence of the imaginary part of the magnetic susceptibility under ac 
magnetic field measurements.[2, 3] From a practical point of view, ac susceptibility experiments are more frequently employed than the determination of hysteresis for the evaluation of SMM properties because not all SMM show hysteresis curve at the operation conditions of the employed equipment and from the ac susceptibility experiments the relaxation time $(\tau)$ can be easily extracted using the generalized Debye model. The dependence of $\tau$ with temperature indicates the different mechanism (Orbach, quantum tunneling, Raman, direct) involved in the relaxation of the magnetization. When the dependence of $\tau$ with temperature follow an Arrhenius law the relaxation process involves the jump of an energy barrier indicating that the main mechanism of relaxation is a thermally-activated process (Orbach mechanism). In this way, an effective $U_{\text {eff }}$ value can be calculated from the dependence of $\tau$ with respect to temperature. It is worth noting that $U_{\text {eff }}$ will be smaller than the maximum value of $|\mathrm{D}| \cdot \mathrm{S}^{2}$ due to the presence of tunneling effects.

Since 1993, when Sessoli et al. detected SMM behavior for the first time at a low temperature in a $\left[\mathrm{Mn}_{12} \mathrm{O}_{12}\left(\mathrm{CH}_{3} \mathrm{COO}\right)_{16}\left(\mathrm{H}_{2} \mathrm{O}\right)_{4}\right]$ complex, usually known as $\mathrm{Mn}_{12}\left(8 \mathrm{Mn}^{\mathrm{III}} 4 \mathrm{Mn}^{\mathrm{IV}}\right)$ with $\mathrm{U}_{\text {eff }}=30 \mathrm{~cm}^{-1}$, [9] many research groups have been searching for new polynuclear systems with large barriers in the hope of devising high-temperature applications (given that current SMMs are normally below $10 \mathrm{~K})$. The goal has usually been to increase the total spin of the molecules by adding more paramagnetic centers to the complexes and also by seeking parallel alignment among the spins (ferromagnetic coupling). However, this approach has not provided substantial improvements in the materials. To date, the best results were obtained in 2007 with a $\mathrm{Mn}_{6}$ complex $(\mathrm{S}=12),\left[\mathrm{Mn}_{6} \mathrm{O}_{2}(\mathrm{Et}-\right.$ sao $\left.)_{6}(\mathrm{PhCOO})_{2}\right]$ (Et-sao: ethyl-salicyladoxime) with six $\mathrm{Mn}^{\mathrm{III}}$ cations; achieved by Brechin et al. which just managed to overcome the barrier $\left(\mathrm{U}_{\text {eff }}=37 \mathrm{~cm}^{-1}\right)$ of the original $\mathrm{Mn}_{12}$ complex.[10-13] Meanwhile, the magnetic anisotropy quantified by the D parameter (which depends on the spinorbit contribution) is in principle a difficult property to predict and/or control. Hence, in many cases (as in those mentioned above) $\mathrm{Mn}^{\mathrm{III}}$ cations are routinely used as the source of magnetic anisotropy.[14] In the case of lanthanide complexes,[15] the spin-orbit is an intrinsic property, while in first row transition metal complexes some coordination requirements are needed to obtain 
large anisotropy (see section 3). Also, heavier transition metal centers with larger spin-orbit coupling could be employed, but their use have been limited due to the fact that they are usually in a low-spin state. Recently, some appealing lanthanide complexes have been reported: two polynuclear $\mathrm{Dy}_{4}$ and $\mathrm{Dy}_{5}$ complexes showing a relaxation barrier around $560 \mathrm{~cm}^{-1}$ with blocking temperatures of 40 K.[16]

\section{Mononuclear Single-Molecule Magnets}

In 2003 a mononuclear complex [ $\mathrm{TbPc}_{2}$ ] containing one $\mathrm{Tb}^{\mathrm{III}}$ cation was reported to exhibit slow magnetization relaxation together with large tunneling effects.[17] Since 2008, several rare earth complexes showing SMM behavior have been reported, among them lanthanide systems containing Kramers $\mathrm{Er}^{\mathrm{III}}$ and Dy ${ }^{\mathrm{III}}$ cations.[18, 19] Some actinide species showing SMM behavior have also been characterized, including several $\mathrm{U}^{\mathrm{III}}$ complexes,[20-25] one $\mathrm{U}^{\mathrm{V}}$ system,[26] as well as one $\mathrm{Np}^{\text {IV }}$ system.[27] These systems have sometimes been called single-ion magnets, though we prefer the term mononuclear single-molecule magnet. It was postulated that the presence of heavy elements with large spin-orbit made possible the appearance of large magnetic anisotropy. Recently, mononuclear single-molecule magnets based on lanthanide cations have been extensively reviewed by Winpenny et al.[28] and Brooker et al.[29]

In 2010, Long and coworkers synthesized an appealing family of mononuclear tetracoordinate $\mathrm{Fe}^{\mathrm{II}}$ complexes[30, 31] which show similar magnetic activity by applying a weak static magnetic field to reduce tunneling effects (field-induced SMM). Recently, some mononuclear complexes containing mainly $\mathrm{Fe}^{\mathrm{II}}$ and $\mathrm{Co}^{\mathrm{II}}$ centers were reported exhibiting exactly the same behavior.[32] Table 1 shows the mononuclear transition metal complexes reported in the literature that show SMM behavior with easy axis (negative $\mathrm{D}$ value) anisotropy, together with some other systems for which the D value has not been determined. From an experimental point of view, the determination of the ZFS parameters using magnetization measurements is not ideal, but large D values prevent the use of the more accurate high-field EPR technique. It is worth mentioning that some $\mathrm{Mn}^{\mathrm{III}}$ mononuclear complexes which do not have very large magnetic anisotropy may nonetheless show slow 
relaxation with very low energy barriers.[33, 34] Finally, two singular cases have been published. The first is a $\mathrm{Ni}^{\mathrm{I}}$ compound showing single-molecule magnet behavior with a $\mathrm{d}^{9}$ electronic configuration and $\mathrm{S}=1 / 2$ total $\operatorname{spin}[35]$. The second is a $\mathrm{Re}^{\mathrm{IV}}$ complex, with a $\mathrm{d}^{3}$ electronic configuration and $S=3 / 2$. [36] This is the first example of third row transition metal mononuclear SMM, despite the well-known tendency of heavier transition metal atoms to adopt low-spin configurations.[37] The analysis of the experimental data reveals that only five compounds $\left(\mathrm{Fe}^{\mathrm{I}}\right.$, $\mathrm{Fe}^{\mathrm{III}}$ and $\mathrm{Co}^{\mathrm{II}}$ systems, see Table 1) show slow relaxation of the magnetization without applying a weak static magnetic field (zero-field SMM) fewer in number than the equivalent lanthanide complexes. Finally, we should also mention the existence of some mononuclear $\mathrm{Ni}^{\mathrm{II}}$ complexes which have very large negative D values (around $200 \mathrm{~cm}^{-1}$ ), but do not exhibit slow relaxation of the magnetization due to the existence of a coupling between $m_{S}= \pm 1 .[38,39]$

Table 1. Mononuclear SMM transition metal complexes with easy axis anisotropy (negative D value) including the coordination mode, $\mathrm{D}(|\mathrm{E}|)$ values in $\mathrm{cm}^{-1}$, the effective barrier $\mathrm{U}_{\text {eff }}\left(\right.$ in $\left.^{-1}\right)$ with the value of the static field $\mathrm{H}_{\text {st }}$ (parenthesis, in Oe) employed in the ac measurements. Mononuclear SMM without an experimental D value have also been included.

\begin{tabular}{|c|c|c|c|c|c|}
\hline Complex & $\mathrm{S}$ & Coordination & $\mathrm{D}(|\mathrm{E}|)$ & $\mathrm{U}_{\text {eff }}\left(\mathrm{H}_{\mathrm{st}}\right)$ & ref. (year) \\
\hline$* \mathrm{Na}\left[\mathrm{tpa}^{t-\mathrm{Bu}} \mathrm{Fe}^{\mathrm{II}}\right]$ & 2 & trigonal pyramid & $-48(0.4)^{\mathrm{a}}$ & $65(1500)$ & {$[30,31](2010)$} \\
\hline$\left[\mathrm{Fe}^{\mathrm{II}}\left(i \mathrm{Pr}_{5} \mathrm{C}_{5}\right)\left(2,6-i \mathrm{Pr}_{2} \mathrm{C}_{6} \mathrm{H}_{3}\right)\right]$ & 2 & $5+1$ & $-51.4(0.32)^{\mathrm{a}}$ & $\begin{array}{c}28(750) \\
100(2500)\end{array}$ & [40] (2011) \\
\hline \multirow[t]{2}{*}[\mathrm{Fe}^{\mathrm{II}}(\mathrm{N}(\mathrm{SiMe}_{3})_{2})_{2}(\mathrm{PCy}_{3})]{} & 2 & trigonal planar & - & $29(600)$ & {$[41](2011)$} \\
\hline & & & $-33(3.4)^{\mathrm{a}-\mathrm{b}}$ & $16(600)$ & [42] (2014) \\
\hline$\left[(\mathrm{PNP}) \mathrm{Fe}^{\mathrm{III}} \mathrm{Cl}_{2}\right]$ & $3 / 2$ & trigonal bipyramid & $-11(<0.11)^{\mathrm{a}}$ & $36(0)$ & {$[43](2012)$} \\
\hline$*\left[\mathrm{Fe}^{\mathrm{II}}\left(\mathrm{N}\left(\mathrm{SiMe}_{3}\right)(\mathrm{Dipp})\right)_{2}\right]$ & 2 & linear & - & $181(500)$ & [44] (2013) \\
\hline$\left[\mathrm{K}\right.$ (crypt-2.2.2)][Fe $\left.\left(\mathrm{C}\left(\mathrm{SiMe}_{3}\right)_{3}\right)_{2}\right]$ & $3 / 2$ & linear & - & $226(0)$ & [45] (2013) \\
\hline$\left.\left[\mathrm{Fe}^{\mathrm{II}} \text { (1-propyltetrazole }\right)_{6}\right]\left(\mathrm{BF}_{4}\right)_{2}$ & 2 & octahedral & $-14.8(0.95)^{\mathrm{c}}$ & $15(2000)$ & [46] (2013) \\
\hline$\left[\mathrm{PhB}(\text { MesIm) })_{3} \mathrm{Fe}^{\mathrm{II}}-\mathrm{N}=\mathrm{PPh}_{3}\right]$ & 2 & tetrahedral & - & $15(1000)$ & [47] (2013) \\
\hline$\left[(\mathrm{cAAC})_{2} \mathrm{Fe}^{\mathrm{I}}\right]\left[\mathrm{B}\left(\mathrm{C}_{6} \mathrm{~F}_{5}\right)_{4}\right]$ & $3 / 2$ & linear & $\begin{array}{c}-22^{\mathrm{a}},-13.6^{\mathrm{b}} \\
-13.6^{\mathrm{c}}\end{array}$ & $<20(3000)$ & [48] (2014) \\
\hline$*\left[\left[\mathrm{CO}^{\mathrm{II}}(\mathrm{ArN}=\mathrm{CMe})_{2}(\mathrm{NPh})\right](\mathrm{NCS})_{2}\right]$ & $3 / 2$ & square pyramid & $-28.0^{\mathrm{b}}$ & $17(2000)$ & [49] (2011) \\
\hline
\end{tabular}




\begin{tabular}{|c|c|c|c|c|c|}
\hline$*\left[\mathrm{PPh}_{4}\right]_{2}\left[\mathrm{Co}{ }^{\mathrm{II}}(\mathrm{SePh})_{4}\right]$ & $3 / 2$ & tetrahedral & $-83^{\mathrm{b}}$ & $19(0)$ & {$[50,51](2011)$} \\
\hline$*\left[\mathrm{Co}^{\mathrm{II}}(\mathrm{L} 1)_{2}\right]$ & $3 / 2$ & tetrahedral & $-41^{\mathrm{a}}$ & $62(1000)$ & [52] (2012) \\
\hline$\left[\left(\mathrm{Co}^{\mathrm{II}} \mathrm{Co}_{3}^{\mathrm{III}}{ }_{3} 2_{6}\right)\left(\mathrm{HNEt}_{3}\right)\right]$ & $3 / 2$ & trigonal prism & $-115(2.8)^{\mathrm{a}}$ & $76(0)$ & [53] (2013) \\
\hline$\left[\mathrm{Co}^{\mathrm{III}} \mathrm{Co}^{\mathrm{II}}\left(\mathrm{H}_{2} \mathrm{~L} 3\right)_{2}(\mathrm{Br})\left(\mathrm{H}_{2} \mathrm{O}\right)\right]$ & $3 / 2$ & octahedral & $\begin{array}{c}-9.7^{\mathrm{a}} \\
|\mathrm{E} / \mathrm{D}|<10^{-4}\end{array}$ & $14.5(1000)$ & [54] (2013) \\
\hline$\left[\mathrm{Co}{ }^{\mathrm{II}}(\mathrm{L} 4)\right]\left[\left(\mathrm{NO}_{3}\right)_{2}\right]$ & $3 / 2$ & trigonal prism & $-72(7)^{\mathrm{a}}$ & $23(2000)$ & [32] (2013) \\
\hline$*\left[\mathrm{Co}^{\mathrm{II}}\left(\mathrm{PPh}_{3}\right)_{2} \mathrm{Cl}_{2}\right]$ & $3 / 2$ & tetrahedral & - & $26(1000)$ & {$[55](2013)$} \\
\hline$\left[\mathrm{Co}^{\mathrm{II}}(\mathrm{hpbdti})_{2}\right]$ & $3 / 2$ & tetrahedral & - & $39.4(2000)$ & [56] (2013) \\
\hline$*\left[\mathrm{Co}^{\mathrm{II}}(\right.$ terpy $\left.) \mathrm{Cl}_{2}\right]$ & $3 / 2$ & square pyramid & - & $19(600)$ & [57] (2013) \\
\hline$*\left[\mathrm{Co}^{\mathrm{II}}\left(\mathrm{N}\left(\mathrm{SiMe}_{3}\right)_{2}\right)_{2}\left(\mathrm{PCy}_{3}\right)\right]$ & $3 / 2$ & trigonal planar & $-82(0.0)^{\mathrm{a}-\mathrm{b}}$ & $19.1(750)$ & [42] (2014) \\
\hline$\left[\mathrm{Co}^{\mathrm{II}}\left(\mathrm{PPh}_{3}\right)_{2} \mathrm{Br}_{2}\right]$ & $3 / 2$ & tetrahedral & $-13^{\mathrm{a}-\mathrm{b}}$ & $\begin{array}{l}25.7(1000) \\
27.8(2000)\end{array}$ & [58] (2014) \\
\hline$*\left[\mathrm{Co}^{\mathrm{II}}\left(\mathrm{Me}_{6}\right.\right.$ tren $\left.) \mathrm{Cl}\right] \mathrm{ClO}_{4}$ & $3 / 2$ & trigonal bipyramid & $\begin{array}{l}-6.2(0.0)^{\mathrm{b}} \\
-8.12(0.0)^{\mathrm{c}}\end{array}$ & - & [59] (2014) \\
\hline$\left[\mathrm{Co}^{\mathrm{II}}\left(\mathrm{Me}_{6}\right.\right.$ tren $\left.)\left(\mathrm{OH}_{2}\right)\right]\left(\mathrm{NO}_{3}\right)_{2}$ & $3 / 2$ & trigonal bipyramid & - & $12.5(1400)$ & {$[60](2014)$} \\
\hline$\left[\mathrm{Co}^{\mathrm{II}}(12 \mathrm{C} 4)_{2}\right]\left(\mathrm{I}_{3}\right)_{2}(12 \mathrm{C} 4)$ & $3 / 2$ & square antiprism & $\begin{array}{l}-38.0(0.75)^{\mathrm{a}} \\
-37.6(0.1)^{\mathrm{b}}\end{array}$ & $17(500)$ & [61] (2014) \\
\hline$*\left[\mathrm{Co}^{\mathrm{II}}\left(\mathrm{AsPh}_{3}\right)_{2} \mathrm{I}_{2}\right]$ & $3 / 2$ & tetrahedral & $-74.7(0.82)^{\mathrm{a}}$ & $22.7(1000)$ & [62] (2014) \\
\hline$\left(\mathrm{Ph}_{4} \mathrm{P}\right)_{2}\left[\mathrm{Co}^{\mathrm{II}}\left(\mathrm{C}_{3} \mathrm{~S}_{5}\right)_{2}\right]$ & $3 / 2$ & tetrahedral & $-161(0)^{\mathrm{a}}$ & $\begin{array}{c}33.9(0) \\
39.9(1000)\end{array}$ & [63] (2014) \\
\hline$*\left[\mathrm{Co}^{\mathrm{II}} \mathrm{L}_{5} \mathrm{Cl}_{2}(\mathrm{MeCN})\right]$ & $3 / 2$ & tetrahedral & $-11.3^{\mathrm{a}-\mathrm{b}}$ & $20.2(2500)$ & {$[64](2015)$} \\
\hline$\left[\mathrm{Ni}^{\mathrm{I}}(6-\mathrm{Mes})_{2}\right] \mathrm{Br}$ & $1 / 2$ & linear & - & $12(600)$ & [35] (2013) \\
\hline$\left[\mathrm{Mn}^{\mathrm{III}}(\mathrm{L} 6)\left(\mathrm{H}_{2} \mathrm{O}\right) \mathrm{Co}^{\mathrm{III}}(\mathrm{CN})_{6}\right]$ & 2 & octahedral & $-3.3^{\mathrm{a}-\mathrm{b}, \mathrm{c}}$ & $11.5(4500)$ & [33] (2013) \\
\hline $\mathrm{Ph}_{4} \mathrm{P}\left[\mathrm{Mn}^{\mathrm{III}}\left(\mathrm{opbaCl}_{2}\right)(\mathrm{py})_{2}\right]$ & 2 & octahedral & $\begin{array}{l}-3.3(0.10)^{\mathrm{a}-\mathrm{b}} \\
-3.4(0.15)^{\mathrm{c}}\end{array}$ & $12.6(1000)$ & [34] (2013) \\
\hline$\left[\mathrm{Cr}^{\mathrm{II}} \mathrm{Cr}_{4}(\mathrm{tpda})_{4} \mathrm{Cl}_{2}\right]$ & 2 & vacant octahedron & $-2.2(0.009)^{\mathrm{c}}$ & $6.4(2500)$ & {$[65](2014)$} \\
\hline$*\left(\mathrm{NBu}_{4}\right)_{2}\left[\mathrm{Re}^{\mathrm{IV}} \mathrm{Br}_{4}(\mathrm{ox})\right]$ & $3 / 2$ & octahedral & $-62.6(13.8)$ & $9.6(1000)$ & [36] (2013) \\
\hline
\end{tabular}

a) values from magnetization fit. b) values from magnetic susceptibility fit. c) values from EPR

* for the families of similar compounds only the complex with larger magnetic anisotropy is shown in the Table $\underline{\mathrm{H}}_{3} \underline{\mathrm{tpa}}^{t-\mathrm{Bu}}=\operatorname{tris}\left(5\right.$-tert-butyl-1H-pyrrol-2-ylmethyl)amine; $\underline{\mathrm{PCy}}_{3}=$ tricyclohexylphosphine; $\underline{\mathrm{PNP}}=\mathrm{N}\left[2-\mathrm{P}(\mathrm{CHMe})_{2}-4-\right.$ methylphenyl $]_{2} ;$ Dipp $=\mathrm{C}_{6} \mathrm{H}_{3}-2,6-\mathrm{Pr}_{2}^{\mathrm{i}} ;$ cAAC $=$ cyclic alkyl(amino) carbenes; $\underline{\mathrm{L} 1}=2-(4,5$-diphenyl-1H-imidazol-2yl)phenol; $\quad \underline{\mathrm{H}}_{2} \underline{\mathrm{L} 2}=$ R-4-bromo-2-((2-hydroxy-1-phenylethylimino)methyl)phenol; $\underline{\mathrm{H}}_{4} \underline{\mathrm{L} 3}=2$ = 2 - ((2-hydroxy-3methoxyphenyl)methylene)amino]-2-(hydroxymethyl)-1,3-propanediol; $\underline{\mathrm{L} 4}=\left(\mathrm{P}(\mathrm{S})\left[\left[\mathrm{N}_{(}\left(\mathrm{CH}_{3}\right) \mathrm{N}=\mathrm{CHC}_{3} \mathrm{~N}_{2} \mathrm{H}_{3}\right]_{3}\right]\right)$; hpbdtiH = 2-(2-hydroxyphenyl)-4,5-bis(2,5-dimethyl(3-thienyl))-1H-imidazole; $\underline{12 \mathrm{C} 4}=12$-crown-4; $\underline{\mathrm{L} 5}=$ 2,3-diphenyl-1,2,3,4tetrazolium-5-thiolate; $\underline{6-\mathrm{Ges}}=1,3$-bis(2,4,6-trimethylphenyl)-3,4,5,6-tetrahydropyrimidin-2-ylidene; $\underline{\mathrm{L} 6}=5$ TMAM(R)-salmen = (R)-N,N'-(1-methylethylene)bis(5-trimethylammoniomethylsalicylideneiminate); $\underline{\mathrm{H}}_{4} \underline{\mathrm{opbaCl}} \underline{2}=$ N,N'-3,4-dichloro-o-phenylenebis(oxamic; acid); $\underline{\mathrm{H}}_{2} \underline{\mathrm{t}} \underline{\mathrm{pda}}=\mathrm{N} 2, \mathrm{N6}$-di(pyridin-2-yl)pyridine-2,6-diamine 
In parallel, the first mononuclear transition metal compound showing slow spin relaxation but with easy plane anisotropy was reported in 2012 by Long and coworkers.[66] Logically, in order to present slow relaxation, those systems must present a half-integer spin value to show a magnetic $\mathrm{Ms}=1 / 2$ Kramers doublet ground state. Almost all the easy plane mononuclear transition metal SMMs reported are based on $\mathrm{Co}^{\mathrm{II}}$ complexes except the recently reported trigonal planar $\mathrm{Fe}^{\mathrm{I}}$ complex (see Table 2). For the bicoordinate $\mathrm{Fe}^{\mathrm{I}}$ complex[45] included in Table 1, the original paper does not indicate the sign of the zero field splitting parameter D, but after carrying out some CASSCF-RASSI calculations (see Table 4), we saw that it corresponds to an easy axis system. Furthermore, a solid-state system $\operatorname{Li}_{2}\left(\mathrm{Li}_{1-\mathrm{x}} \mathrm{Fe}\right) \mathrm{N}$ with the same coordination of the $\mathrm{Fe}^{\mathrm{I}}$ centers has recently been described which also shows large magnetic anisotropy.[67] Also, one easy plane mononuclear Dy ${ }^{\text {III }}$ complex showing small relaxation has been reported[68] even though mononuclear lanthanide SMMs usually have magnetic anisotropy and are strongly axial.

Table 2. Mononuclear SMM transition metal complexes that show easy plane anisotropy (positive $\mathrm{D}$ value) including the coordination mode, $\mathrm{D}(|\mathrm{E}|)$ values in $\mathrm{cm}^{-1}$, the effective barrier $\mathrm{U}_{\mathrm{eff}}\left(\mathrm{in} \mathrm{cm}^{-1}\right)$ with the value of the static field $\mathrm{H}_{\mathrm{st}}$ (parenthesis, in Oe) employed in the ac measurements.

\begin{tabular}{|c|c|c|c|c|c|}
\hline Complex & $\mathrm{S}$ & Coordination & $\mathrm{D}(|\mathrm{E}|)$ & $\mathrm{U}_{\text {eff }}\left(\mathrm{H}_{\mathrm{st}}\right)$ & ref. (year) \\
\hline$\left[\mathrm{Co}{ }^{\mathrm{II}} \mathrm{Cl}(3 \mathrm{G})\right]\left(\mathrm{CF}_{3} \mathrm{SO}_{3}\right)$ & $3 / 2$ & tetrahedral & $+12.7(1.2)^{\mathrm{c}}$ & $24(1500)$ & [66] (2012) \\
\hline$c i s-\left[\mathrm{Co}^{\mathrm{II}}(\mathrm{dmphen})_{2}(\mathrm{NCS})_{2}\right]$ & $3 / 2$ & octahedral & $+98(8.4)^{\mathrm{a}}$ & $18.1(2500)$ & [69] (2012) \\
\hline $\mathrm{K}\left[\mathrm{Co}^{\mathrm{II}}\left(\mathrm{N}\left[\mathrm{CH}_{2} \mathrm{C}(\mathrm{O}) \mathrm{NC}\left(\mathrm{CH}_{3}\right)_{3}\right]_{3}\right)\right]$ & $3 / 2$ & trigonal pyramid & $+16(0.0)^{\mathrm{a}}$ & $8.7(1500)$ & [32] (2013) \\
\hline$\left[\mathrm{Co}(\mu-\mathrm{II} 7)(\mu-\mathrm{OAc}) \mathrm{Y}\left(\mathrm{NO}_{3}\right)_{2}\right]$ & $3 / 2$ & octahedral & $+41.7(1.3)^{\mathrm{a}-\mathrm{b}}$ & $15.7(1000)$ & [70] (2013) \\
\hline$\left[\mathrm{Co}^{\mathrm{II}}(\mathrm{dmphen}) \mathrm{Br}_{2}\right]$ & $3 / 2$ & tetrahedral & $\begin{array}{c}+10.6(0.01)^{\mathrm{a}} \\
+11.7(2.6)^{\mathrm{c}}\end{array}$ & $22.9(1000)$ & [71] (2013) \\
\hline$\left[(\mathrm{L} 8)_{4} \mathrm{Co}^{\mathrm{II}} \mathrm{Co}_{2}^{\mathrm{IIII}}\left(\mathrm{H}_{2} \mathrm{O}\right)_{2}\right]\left(\mathrm{NO}_{3}\right)$ & $3 / 2$ & octahedral & $\begin{array}{l}+29.8(\leq 0.65)^{\mathrm{a}} \\
+31.9(3.0)^{\mathrm{c}}\end{array}$ & $5.6(1000)$ & [72] (2013) \\
\hline$\left[\mathrm{Co}^{\mathrm{III}}(\mathrm{abpt})_{2}(\mathrm{tcm})_{2}\right]$ & $3 / 2$ & octahedral & $+48(13)^{\mathrm{a}-\mathrm{b}}$ & $59.9(3000)$ & [73] (2014) \\
\hline$\left[\mathrm{Co}^{\mathrm{II}}(\mathrm{acac})_{2}\left(\mathrm{H}_{2} \mathrm{O}\right)_{2}\right]$ & $3 / 2$ & octahedral & $+57(17.7)^{\mathrm{a}-\mathrm{c}}$ & - & [74] (2014) \\
\hline$*\left[\mathrm{Co}^{\mathrm{II}}\left(\mathrm{H}_{2} \mathrm{dapb}\right)\left(\mathrm{H}_{2} \mathrm{O}\right)\left(\mathrm{NO}_{3}\right)\right]\left(\mathrm{NO}_{3}\right)$ & $3 / 2$ & $\begin{array}{l}\text { pentagonal } \\
\text { bipyramid }\end{array}$ & $+32.4(0)^{\mathrm{a}}$ & $56.3(1000)$ & {$[75](2014)$} \\
\hline$*\left[\mathrm{Co}^{\mathrm{II}} \mathrm{L} 9 \mathrm{Cl}_{2}(\mathrm{MeCN})\right]$ & $3 / 2$ & tetrahedral & $+15.6^{\mathrm{a}-\mathrm{b}}$ & $10.3(2500)$ & {$[64](2015)$} \\
\hline$\left[(\mathrm{cAAC})_{2} \mathrm{Fe}^{\mathrm{I}} \mathrm{Cl}\right]$ & $3 / 2$ & trigonal planar & $+20.4(0.2)^{\mathrm{a}}$ & $22.4(500)$ & {$[48](2014)$} \\
\hline
\end{tabular}


a) values from magnetization fit. b) values from magnetic susceptibility fit. c) values from EPR

* for the families of similar compounds only the complex with larger magnetic anisotropy is shown in the Table $\underline{3 \mathrm{G}}=1,1,1$-tris-[2N-(1,1,3,3-tetramethylguanidino)methyl] ethane; $\underline{\mathrm{dmphen}}=2,9$-dimethyl-1,10-phenanthroline; $\underline{\mathrm{H}}_{2} \underline{\mathrm{L} 7}=$ N,N',N'-trimethyl-N,N"'-bis(2-hydroxy-3-methoxy-5-methylbenzyl)-diethylenetriamine; HL8 $=(E)$ - $N$ '-(pyridin-2ylmethylene)pyrazine-2-carbohydrazide; abpt $=4$-amino-3,5-bis(2-pyridyl)-1,2,4-triazole; $\underline{\mathrm{tcm}}=$ tricyanomethanide anion; $\underline{\mathrm{H}_{2}} \underline{\mathrm{dapb}}=2,6$-diacetylpyridine bis(benzoylhydrazine); $\underline{\mathrm{L} 9}=2,3$-diphenyl-1,2,3,4-tetrazolium-5-olate.

\section{Rationalization of the Magnetic Anisotropy of Mononuclear Transition Metal SMM}

For many years, magnetic anisotropy was not generally considered in detail for a rational design of new single-molecule magnets with high anisotropic energy barrier. Members of our group [76] and other authors[77] have shown that in polynuclear systems, the predominance of ferromagnetic interactions, and consequently large total spin values, lead to small magnetic anisotropy, and the $\mathrm{D} \cdot \mathrm{S}^{2}$ value is practically constant for a given family of complexes. However, in recent years the situation has changed substantially. For the systems with large magnetic anisotropy, theoretical studies based on CASSCF/CASPT2 methods including spin-orbit effects provide a very helpful tool for analyzing and quantifying the magnetic anisotropy[78] through the calculation of the D and E zero-field splitting parameters or the g components (for the lanthanides). These methods provide accurate results for mononuclear complexes and, given that magnetic anisotropy is a local property, they can also provide valuable information about polynuclear SMMs through calculations on truncated mononuclear fragments.[79] Thus, despite the high computational requirements of CASSCF/CASPT2 methods, polynuclear complexes can also be accurately handled. DFT methods also provide reasonable values of the zero field splitting for polynuclear complexes with small magnetic anisotropy, but they are unable to give proper results of complexes with high magnetic anisotropy.[80]

Usually in the analysis of the experimental data, the zero-field splitting Hamiltonian is described as indicated in Eq. 1. In such expression, a $K S^{2}$ term was neglected since it uniformly shifts all the energy levels in order to give a traceless D tensor.[7, 8] It is worth clarifying that in the electronic structure calculations, the $\mathrm{D}$ tensor is not traceless because the constant $K S^{2}$ term is not removed 
and the zero-field splitting parameters (D and E) can be calculated from the three elements of the diagonalized D tensor (see Eq. 2).[81, 82]

$$
D=D_{z z}-\left(D_{x x}+D_{y y}\right) / 2 ; E=\left(D_{x x}-D_{y y}\right) / 2
$$

The elements of such a tensor can be obtained from:

$$
D_{k l}=-\frac{\xi_{e f f}^{2}}{4 S^{2}} \sum_{i, p} \frac{\left\langle\varphi_{i}\left|l_{k}\right| \varphi_{p}\right\rangle\left\langle\varphi_{p}\left|l_{l}\right| \varphi_{i}\right\rangle}{\varepsilon_{p}-\varepsilon_{i}}-\frac{\xi_{e f f}^{2}}{4 S^{2}} \sum_{p, a} \frac{\left\langle\varphi_{p}\left|l_{k}\right| \varphi_{a}\right\rangle\left\langle\varphi_{a}\left|l_{l}\right| \varphi_{p}\right\rangle}{\varepsilon_{a}-\varepsilon_{p}}
$$

where $\zeta_{\text {eff }}^{2}$ is the spin-orbital coupling constant, $l_{k}$ is the k-component of the angular momentum operator and $\varphi$ are the molecular orbitals (with orbital energy $\varepsilon$ ) with the subindex $i, p$ or $a$ to indicate double-occupied, singly-occupied or empty orbitals respectively. In quantum chemistry codes, the calculation of the zero-field splitting parameters is slightly different. Thus, in post Hartree-Fock methods, ZFS parameters are directly calculated from the energy differences with excited states[78] or by using effective Hamiltonian expressions including such parameters to reproduce the calculated energy values for ground or excited states.[83, 84] For non-traceless D tensor, the labeling of the $x, y$ and $z$ directions should be performed by comparison of the differences between the diagonal elements of the $\mathrm{D}$ tensor, while for a traceless $\mathrm{D}$ tensor, the $z$ direction corresponds to the maximum component in absolute value. In order to qualitatively elucidate the origin of the D values, we analyzed the different terms, $D_{i i}$, using Eq. 3 as a function of the coordination of the metal (the splitting of the d orbitals) and the electronic configuration.[32] This approach may make the analysis of the magnetic anisotropy considerably easier, since it allows us to consider a simple theoretical model in order to estimate the first excitation energies. Such terms will be the most important in determining the $D_{i i}$ components that depend inversely on the energy of the orbitals (or excitation energies, if instead of orbitals we consider states).

In order to build the qualitative model, we considered the following features. (i) The sign of D, assuming that $\mathrm{D}$ tensor is not traceless, will depend on the relative values of the $D_{z z}$ and $\left(D_{x x}+\right.$ $D_{y y}$ ) $/ 2$ terms. Such tensor elements calculated with our simple model (only including the main non 
spin-flip excitations, Eq. 3) are strictly negative. In DFT or ab initio calculations, such terms can be positive if the spin-flip contributions are predominant. Thus, in our model if $\left|D_{z z}\right|$ is larger than $\mid\left(D_{x x}\right.$ $\left.+D_{y y}\right) / 2$, the $D$ value is negative, while the opposite case leads to a positive $D$ value. (ii) The magnitude of the $D_{i i}$ components depends mainly on two factors: the $m_{l}$ values of the orbitals involved in the integrals with the angular momentum operator (Eq. 3, as in the magic pentagon commonly employed in EPR), and the energy difference between the pairs of orbitals that can be qualitatively estimated by a simple method like the extended Hückel method by considering only the excitations with the same multiplicity (Eq. 3). Thus, significant contributions to the integrals with the z-component of the angular momentum operator, $l_{z}$, are obtained when the pair of orbitals

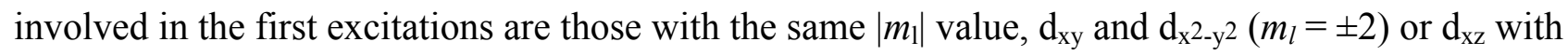
$\mathrm{d}_{\mathrm{yz}}\left(m_{l}= \pm 1\right)$. For the $D_{x x}$ and $D_{y y}$ terms, larger integral values will be related to $m_{1}$ changes of \pm 1 in the orbitals involved.[82]

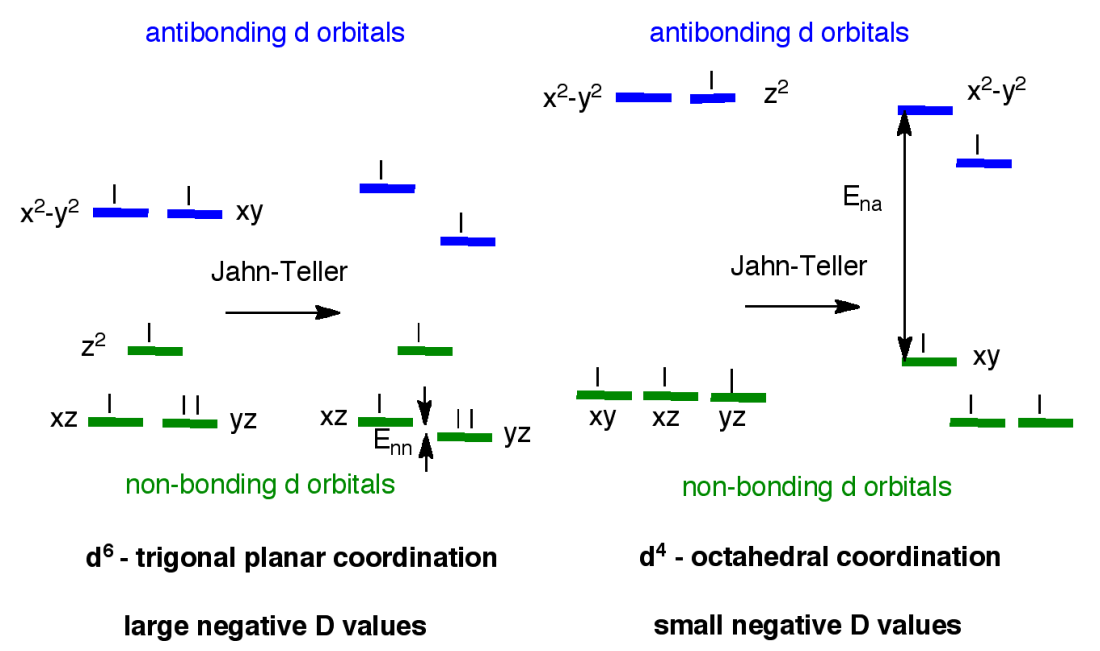

Figure 1. Splitting of the d orbitals due to the Jahn-Teller effect for two cases with negative $D$ values: $\mathrm{d}^{6}$-trigonal planar coordination (left) and $\mathrm{d}^{4}$-octahedral coordination (right). The energy difference indicated by the arrow in each case corresponds to the first excitation which leads to the main contribution to $D_{z z}$ (and $D$, see Eqs. 1 and 2). The smaller the excitation energy, the larger $|\mathrm{D}|$ becomes.

For instance, a $\mathrm{Fe}^{\mathrm{II}}$ complex ( $\mathrm{d}^{6}$ electronic configuration) displaying trigonal planar coordination (e.g., the $\left[\mathrm{Fe}^{\mathrm{II}}\left(\mathrm{N}\left(\mathrm{SiMe}_{3}\right)_{2}\right)_{2}\left(\mathrm{PCy}_{3}\right)\right]$ complex in Table 1) presents a first-order Jahn-Teller effect which breaks the degeneracy of the non-bonding $d_{x z}$ and $d_{y z}$ orbitals (see Figure 1). The first 
excitation energy will involve these two orbitals which have the same $\left|m_{1}\right|$ value and results in a large contribution to the $\mathrm{D}_{\mathrm{zz}}$ component, and consequently gives rise to a large negative $\mathrm{D}$ value. The non-bonding nature of these orbitals favors high values of $|\mathrm{D}|$ because even large geometrical distortions will result in small energy $\left(E_{n n}\right)$ differences between these two $d$ orbitals (Eq. 3). However, for systems containing a $\mathrm{Mn}^{\mathrm{III}}$ cation $\left(\mathrm{d}^{4}\right)$ with elongation of the axial $\mathrm{M}-\mathrm{L}$ distances, which has been widely employed to induce magnetic anisotropy, the $D_{z z}$ contribution will involve large excitation energies $\left(E_{n a}\right)$ from the non-bonding $d_{x y}$ to the antibonding $d_{x^{2}-y^{2}}$ orbital (see Figure 1). Such large energy differences in Eq. 3 will lead to a small negative D value (see Table 1, which shows two $\mathrm{Mn}^{\mathrm{III}}$ complexes with relatively low anisotropy but still slow relaxation of the magnetization).

Table 3 presents the calculated predictions of ZFS parameters for high-spin mononuclear complexes with ammonia ligands and employing $\mathrm{Fe}^{\mathrm{II}}$ cations for the calculations using the extended Hückel method to calculate the orbital energies (an equivalent Table with $\pi$-donor chloride ligands was provided as Supplementary Information in ref. [32]). This model is mainly applicable in first-row transition metal complexes, while for the second- and third-rows, only those complexes with low coordination numbers that might reach a high-spin configuration can be considered. For the $\mathrm{d}^{1}$ and $d^{9}$ electronic configurations, the $D$ value is not properly defined but there is a $g$ tensor that can be used to quantify the magnetic anisotropy. There are some examples in Table 3 which can have D values of opposite sign depending on the symmetry of the distortion caused by the Jahn-Teller effect (i.e., octahedral $\mathrm{Mn}^{\mathrm{III}}$ cations with axial elongation of the ligands result in small negative D values, while compression results in positive D values). Furthermore, there are some cases with two possible D values of the same sign (e.g.: large or small negative values represented by green and blue squares respectively in Table 3) since the magnitude of D will depend on the degree of distortion induced by the Jahn-Teller effect. There are also some complexes with three possible D values due to the presence of triply degenerate orbitals which give different magnetic anisotropies depending on the relative orbital stabilities produced by the Jahn-Teller distortion. 
Table 3. Estimation of the $\mathrm{D}$ values for high-spin mononuclear transition metal complexes with different electronic configurations and coordination modes using ammonia ligands. Green and blue symbols indicate large and small negative values, while red and orange represent large and small positive values respectively. Green and red (orange) circles correspond to the already reported easy axis and easy plane systems, respectively (see Tables 1 and 2). As the criterion for assigning large or small D values, we consider that if the energy difference between the two orbitals involved in Eq. 3 is larger than 0.03 a.u. the D value must be small. [32]

\begin{tabular}{l}
\hline \\
\hline linear-2 \\
divacant tetrahedron-2 \\
tetravacant octahedron-2 \\
\hline trigonal planar-3 \\
vacant tetrahedron-3 \\
fac-trivacant octahedron-3 \\
mer-trivacant octahedron-3 \\
\hline square-4 \\
tetrahedron-4 \\
seesaw-4 \\
trigonal pyramid-4 \\
pentagon-5 \\
vacant octahedron-5 \\
trigonal bipyramid-5 \\
square pyramid-5 \\
hexagon-6 \\
pentagonal pyramid-6 \\
octahedron-6 \\
trigonal prism-6 \\
heptagon-7 \\
hexagonal pyramid-7 \\
pentagonal bipyramid-7 \\
capped octahedron-7 \\
capped trigonal prism-7 \\
octagon-8 \\
heptagonal pyramid-8 \\
hexagonal bipyramid-8 \\
cube-8 \\
square antiprism-8 \\
dodecahedron-8 \\
biaugmented trigonal prism-8
\end{tabular}


The results compiled in Table 3 establish a model that predicts the sign and magnitudes of the magnetic anisotropy (more than forty compounds are included in Tables 1 and 2). It is worth noting the case of a trigonal planar $\mathrm{Co}^{\mathrm{II}}$ complex, which was expected to be an easy plane system.[42] However, the authors have fitted the magnetization and susceptibility measurements with a negative $\mathrm{D}$ value but very close to the $\mathrm{E} / \mathrm{D}=1 / 3$ limit, even though the $\mathrm{CASSCF}$ calculations reported in the original paper also provide a positive D value. Among the systems reported, there are two exceptions to the predictions of the sign using Table 3: (i) The bicoordinate $\mathrm{Fe}^{\mathrm{I}}$ complex[45], which according to the model should be easy plane (in the original paper the sign of the value was not indicated, but our calculations indicate easy axis behavior). This disagreement is due to the fact that, surprisingly, the most stable $d$ orbital is $d_{z^{2}}$ even though it is the orbital oriented towards the two ligands, and this cannot be reproduced by the extended Hückel method; (ii) a perfectly-symmetric trigonal bipyramid $\mathrm{Co}^{\mathrm{II}}$ complex for which the model predicts a positive D value; however, the authors indicate that the ground state has a very high multiconfigurational character due to the high symmetry, and even though the most weighted configuration has positive D (as predicted with our model) the average with all the configuration leads to a negative $\mathrm{D}$ value.[59]

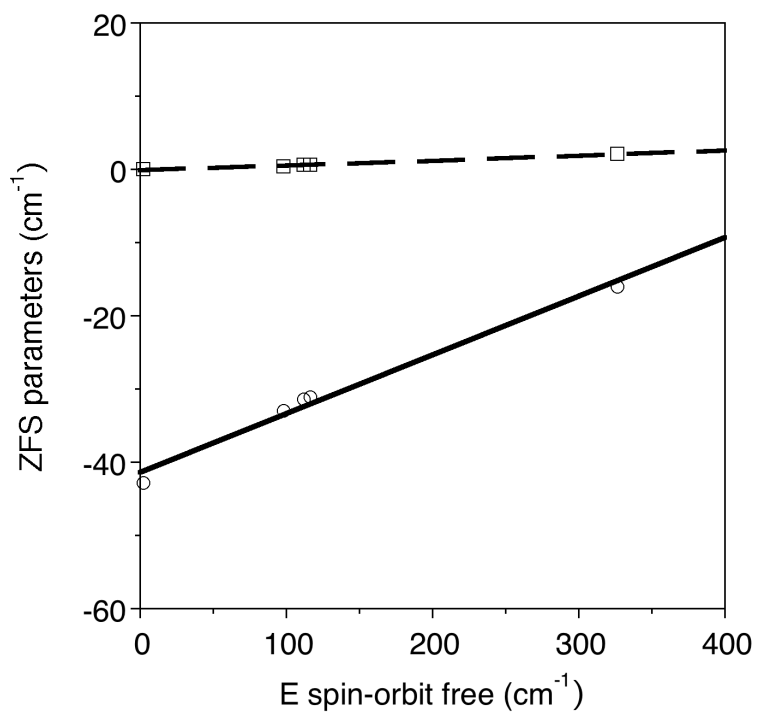

Figure 2. Dependence of the calculated zero-field splitting parameters D and E (circles and squares respectively) for Long's mononuclear tetracoordinate $\mathrm{Fe}^{\mathrm{II}}$ complexes with first spin-orbit free excitation energy $\left(\Delta \mathrm{E}_{1}\right)$ calculated with the CASSCF method.[85] 
A quantitative theoretical study of the magnetic anisotropy of the first family of mononuclear tetracoordinate $\mathrm{Fe}^{\mathrm{II}}$ complexes showing field-induced SMM behavior, synthesized by Long and coworkers, was carried out using a CASSCF approach including spin-effects (RASSI method).[85, 86] This theoretical approach has been considered as the standard procedure for the study of systems of this kind (see reported values for mononuclear transition metal complexes in Table 4). Usually, the inclusion of dynamical correlation effects (CASPT2 or NEVPT2 methods) does not significantly change the CASSCF values. From the analysis of the $\mathrm{Fe}^{\mathrm{II}}$ family of complexes (see Fig. 2), the key parameter for the presence of a large magnetic anisotropy is small first excitation energy (see also the $\Delta \mathrm{E}_{1}$ values in Table 4) in the CASSCF calculation which will lead to a large magnetic anisotropy when the spin-orbit effects are included (Equation 3).[85] Taking these drawbacks into account, reasonable agreement between the experimental and theoretical results should still be found (see Table 4). If the calculated first excitation energy without spin-orbit contribution correlates with the $\mathrm{D}$ value, the equivalent energy but including the spin-orbit effects would give a theoretical estimation of the magnetic anisotropic energy barrier. It should be borne mind that this calculated barrier value should be slightly larger than the experimental ones due to the existence of tunneling effects that are not considered in the calculations.

Table 4. Reported CASSCF/CASPT2+RASSI values of D and $|E|$ (in $\mathrm{cm}^{-1}$ ), ZFS parameters for some mononuclear SMM complexes, and first excitation energies (in $\mathrm{cm}^{-1}$ ) calculated at the spinfree CASSCF (or CASPT2 in bold) level $\left(\Delta \mathrm{E}_{1}\right)$ and after the inclusion of spin-orbit effects $\left(\delta \mathrm{E}_{1}\right)$.

\begin{tabular}{lcccccc}
\hline Complexes & $\mathrm{D}_{\text {exp }}\left(\left|\mathrm{E}_{\text {exp }}\right|\right)$ & $\mathrm{U}_{\text {eff }}(\mathrm{H})$ & $\mathrm{D}_{\text {calc }}\left(\left|\mathrm{E}_{\text {calc }}\right|\right)$ & $\Delta \mathrm{E}_{1}$ & $\delta \mathrm{E}_{1}$ & ref. \\
\hline $\mathrm{K}\left[\mathrm{tpa}^{\mathrm{Mes}} \mathrm{Fe}^{\mathrm{II}}\right]$ & $-44(2.2)$ & $42(1500)$ & $-31.4(0.6)$ & $-{ }^{\mathrm{c}}$ & $73.2^{\mathrm{a}}$ & {$[85]$} \\
$\mathrm{Na}\left[\mathrm{tpa}^{\mathrm{Ph}} \mathrm{Fe}^{\mathrm{II}}\right] \cdot 3 \mathrm{DME}$ & $-26(5)$ & $25(1500)$ & $-31.1(0.6)$ & $-{ }^{\mathrm{c}}$ & $72.3^{\mathrm{a}}$ & {$[85]$} \\
$\mathrm{K}\left[\mathrm{tpa}^{\mathrm{DFP}} \mathrm{Fe}^{\mathrm{II}}\right] \cdot 2 \mathrm{DME}$ & $-6.2(0.1)$ & - & $-16(2.1)$ & $--^{\mathrm{c}}$ & $40.2^{\mathrm{a}}$ & {$[85]$} \\
$\mathrm{Na}\left[\mathrm{tpa}^{t-\mathrm{Bu}^{\mathrm{II}}} \mathrm{Fe}^{\mathrm{II}}\right] \cdot \mathrm{THF}$ & $-48(0.4)$ & $65(1500)$ & $-42.8(0.001)$ & ${ }^{c}$ & $81.4^{\mathrm{a}}$ & {$[85]$} \\
{$\left[\mathrm{Fe}^{\mathrm{II}}\left(i \mathrm{Pr}_{5} \mathrm{C}_{5}\right)\left(2,6-i \mathrm{Pr}_{2} \mathrm{C}_{6} \mathrm{H}_{3}\right)\right]$} & -51.4 & $100(2500)$ & $-72.9(1.1)$ & $177^{\mathrm{c}}$ & - & {$[32]$} \\
{$\left[\mathrm{Fe}^{\mathrm{II}}\left(\mathrm{N}(\mathrm{TMS})_{2}\right)_{2}\left(\mathrm{PCy}_{3}\right)\right]$} & $-0.32)$ & $16(600)$ & $-53.2(0.53)$ & $477.9^{\mathrm{d}}$ & - & {$[42]$} \\
& $-33(3.4)$ & & $-54.7(1.6)$ & $289^{\mathrm{c}}$ & - & {$[32]$} \\
\hline
\end{tabular}




\begin{tabular}{|c|c|c|c|c|c|c|}
\hline$\left[\mathrm{Fe}^{\mathrm{II}}\left(\mathrm{N}\left(\mathrm{SiMe}_{3}\right)(\mathrm{Dipp})\right)_{2}\right]$ & - & $181(500)$ & - & $164^{\mathrm{d}}$ & $189.8^{\mathrm{a}}$ & {$[87]$} \\
\hline$\left[\mathrm{Fe}^{\mathrm{II}}\left[\mathrm{C}\left(\mathrm{SiMe}_{3}\right)_{3}\right]_{2}\right]$ & - & $146(500)$ & - & $92^{\mathrm{d}}$ & $195.2^{\mathrm{a}}$ & [87] \\
\hline$\left[\mathrm{Fe}^{\mathrm{II}}\left[\mathrm{N}(\mathrm{H}) \mathrm{Ar}^{\prime}\right]_{2}\right]$ & - & $109(1800)$ & - & $241^{\mathrm{d}}$ & $176.4^{\mathrm{a}}$ & [87] \\
\hline$\left[\mathrm{Fe}^{\mathrm{II}}\left[\mathrm{N}(\mathrm{H}) \mathrm{Ar}^{*}\right]_{2}\right]$ & - & $104(875)$ & - & $381^{\mathrm{d}}$ & $158.4^{\mathrm{a}}$ & {$[87]$} \\
\hline$\left[\mathrm{Fe}^{\mathrm{II}}(\mathrm{OAr})_{2}\right]$ & - & $43(2500)$ & - & $\mathbf{2 2 2}^{\mathrm{d}}$ & $183.9^{\mathrm{a}}$ & {$[87]$} \\
\hline$\left[\mathrm{Fe}^{\mathrm{II}}\left[\mathrm{N}(\mathrm{H}) \mathrm{Ar}_{2}\right]\right.$ & - & no maximum & - & $1246^{\mathrm{d}}$ & $78.1^{\mathrm{a}}$ & [87] \\
\hline$[\mathrm{K}($ crypt $)]\left[\mathrm{Fe}^{\mathrm{I}}\left(\mathrm{C}\left(\mathrm{SiMe}_{3}\right)_{3}\right)_{2}\right]$ & - & $226(0)$ & - & $27.849 .0^{\mathrm{d}}$ & $198.7 \mathbf{2 1 0 . 1}$ & [44] \\
\hline$\left[(\mathrm{cAAC})_{2} \mathrm{Fe}^{\mathrm{I}}\right]\left[\mathrm{B}\left(\mathrm{C}_{6} \mathrm{~F}_{5}\right)_{4}\right]$ & -13.6 & $<20(3000)$ & $\begin{array}{c}-103.2(0.03) \\
-\mathbf{1 0 2 . 5}(0.04) \\
-b\end{array}$ & $\begin{array}{l}29.3 \mathbf{5 2 . 2}^{\mathrm{c}} \\
571 \mathbf{2 1 0 4}^{\mathrm{c}}\end{array}$ & $\begin{array}{c}206 \mathbf{2 0 5} \\
43.5 \mathbf{3 9 . 0}\end{array}$ & $\begin{array}{l}\text { This } \\
\text { work } \\
{[48]}\end{array}$ \\
\hline$\left[\mathrm{Co}^{\mathrm{II}}\left[(\mathrm{ArN}=\mathrm{CPh})_{2}(\mathrm{NPh})\right](\mathrm{NCS})_{2}\right]$ & -28.2 & $17(2000)$ & $-121.7(16.8)$ & $1197^{\mathrm{c}}$ & - & {$[32]$} \\
\hline$\left[\mathrm{Co}^{\mathrm{II}}\left[(\mathrm{ArN}=\mathrm{CMe})_{2}(\mathrm{NPh})\right](\mathrm{NCS})_{2}\right]$ & -28.1 & $11(2000)$ & $-62.1(10.5)$ & $923^{\mathrm{c}}$ & - & {$[32]$} \\
\hline$\left[\mathrm{PPh}_{4}\right]_{2}\left[\mathrm{Co}{ }^{\mathrm{II}}(\mathrm{SPh})_{4}\right]$ & $-74(0.01)$ & $21(0)$ & $-52.2(0.6)$ & $389^{\mathrm{c}}$ & - & {$[32]$} \\
\hline & & & $-52.1(0.6)$ & $1198^{\mathrm{c}}$ & 104.3 & $\begin{array}{l}\text { This } \\
\text { work }\end{array}$ \\
\hline$\left[\left(\mathrm{Co}^{\mathrm{II}} \mathrm{Co}^{\mathrm{IIII}}{ }_{3} \mathrm{~L}_{6}\right)\left(\mathrm{HNEt}_{3}\right)\right]$ & $-115(2.8)$ & $76(0)$ & $-107(2.7)$ & $--^{c}$ & 216 & [53] \\
\hline$[\mathrm{Co}(\mathrm{L} 4)]\left[\left(\mathrm{NO}_{3}\right)_{2}\right]$ & $-72(7)$ & $23(2000)$ & $-141(2.2)$ & $-{ }^{c}$ & - & {$[32]$} \\
\hline & & & $-142(2.3)$ & $95.2^{\mathrm{c}}$ & 283.1 & $\begin{array}{l}\text { This } \\
\text { work }\end{array}$ \\
\hline$\left[\mathrm{Co}^{\mathrm{II}}\left(\mathrm{PPh}_{3}\right)_{2} \mathrm{Cl}_{2}\right]$ & - & $25.8(1000)$ & $-16.2(0.9)$ & $-{ }^{c}$ & - & {$[55]$} \\
\hline$\left[\mathrm{Co}^{\mathrm{II}}(\mathrm{DPEphos}) \mathrm{Cl}_{2}\right]$ & - & $24.3(1000)$ & $-14.4(1.7)$ & $-{ }^{c}$ & - & {$[55]$} \\
\hline$\left[\mathrm{Co}^{\mathrm{II}}\right.$ (Xantphos)Cl $\left.\mathrm{Cl}_{2}\right]$ & - & $20.8(1000)$ & $-15.4(1.3)$ & $-{ }^{c}$ & - & {$[55]$} \\
\hline$\left[\mathrm{Co}^{\mathrm{II}}(\right.$ terpy $\left.) \mathrm{Cl}_{2}\right]$ & - & $19(600)$ & - & $212 \mathbf{2 5 1}^{\mathrm{c}}$ & 194199 & {$[57]$} \\
\hline$\left[\mathrm{Co}^{\mathrm{II}}\left(\mathrm{N}\left(\mathrm{SiMe}_{3}\right)_{2}\right)_{2}\left(\mathrm{PCy}_{3}\right)\right]$ & $-82(0.0)$ & $19.1(750)$ & $\begin{array}{l} \pm 71.8 \\
(20.1)^{\mathrm{b}}\end{array}$ & $1489^{\mathrm{d}}$ & - & [42] \\
\hline$\left[\mathrm{Co}^{\mathrm{II}}\left(\mathrm{N}\left(\mathrm{SiMe}_{3}\right)_{2}\right)_{2}(\mathrm{THF})\right]$ & $-72(13.5)$ & $18.1(600)$ & $\begin{array}{l} \pm 77.1 \\
(24.7)^{\mathrm{b}}\end{array}$ & $1197^{\mathrm{d}}$ & - & {$[42]$} \\
\hline$\left[\mathrm{Li}\left(15\right.\right.$-crown-5)] $\left[\mathrm{Co}\left[\mathrm{N}\left(\mathrm{SiMe}_{3}\right)_{2}\right]_{3}\right]$ & $-57(12.7)$ & $16.1(800)$ & $\pm 97.5(24.4)$ & $504^{\mathrm{d}}$ & - & {$[42]$} \\
\hline$\left[\mathrm{Co}^{\mathrm{II}}\left(\mathrm{Me}_{6}\right.\right.$ tren $\left.) \mathrm{Cl}\right] \mathrm{ClO}_{4}$ & $-8.12(0.0)$ & - & $-16.5-9.7$ & $\begin{array}{l}2521 \\
\mathbf{3 8 6 1}^{\mathrm{d}}\end{array}$ & - & {$[59]$} \\
\hline$\left[\mathrm{Co}^{\mathrm{II}}\left(\mathrm{Me}_{6}\right.\right.$ tren $\left.) \mathrm{Br}\right] \mathrm{Br}$ & $-2.4(0.0)$ & - & $-4.7-2.4$ & $\begin{array}{c}3077 \\
\mathbf{4 6 1 2}^{\mathrm{d}}\end{array}$ & - & {$[59]$} \\
\hline$\left[\mathrm{Co}^{\mathrm{II}}(12 \mathrm{C} 4)_{2}\right]\left(\mathrm{I}_{3}\right)_{2}(12 \mathrm{C} 4)$ & $-161(0)^{\mathrm{a}}$ & $33.9(0)$ & $-70.1(1.0)$ & $-^{c}$ & - & {$[61]$} \\
\hline$\left[\mathrm{Co}^{\mathrm{II}} \mathrm{L}_{5} \mathrm{Cl}_{2}(\mathrm{MeCN})\right]$ & -11.3 & $20.2(2500)$ & $-11.3(3.1)$ & $2343^{c}$ & 33.6 & {$[64]$} \\
\hline$*\left[\mathrm{Co}^{\mathrm{II}} \mathrm{L} \mathrm{Br}_{2}(\mathrm{MeCN})\right]$ & -10.3 & $13.8(2500)$ & $-16.6(2.7)$ & $1966^{\mathrm{c}}$ & 34.5 & {$[64]$} \\
\hline $\mathrm{Ph}_{4} \mathrm{P}\left[\mathrm{Mn}^{\mathrm{III}}\left(\mathrm{opbaCl}_{2}\right)(\mathrm{py})_{2}\right]$ & $-3.4(0.15)$ & $12.6(1000)$ & $-3.47(0.05)$ & $-{ }^{d}$ & - & [34] \\
\hline \multirow[t]{2}{*}{$\left(\mathrm{NBu}_{4}\right)_{2}\left[\mathrm{Re}^{\mathrm{IV}} \mathrm{Br}_{4}(\mathrm{ox})\right]$} & $\begin{array}{l}-62.6 \\
(13.8)\end{array}$ & $9.6(1000)$ & $-53.4(12.3)$ & $-{ }^{d}$ & - & {$[36]$} \\
\hline & & & $\begin{array}{l}-81.5(20.8) \\
\mathbf{1 2 4 . 8 ( 2 7 . 1 )}\end{array}$ & $\begin{array}{l}13043 \\
\mathbf{7 8 7 1}^{\mathrm{c}}\end{array}$ & 178266 & $\begin{array}{l}\text { This } \\
\text { work }\end{array}$ \\
\hline
\end{tabular}




\begin{tabular}{|c|c|c|c|c|c|c|}
\hline$\left(\mathrm{NBu}_{4}\right)_{2}\left[\mathrm{Re}^{\mathrm{IV}} \mathrm{Cl}_{4}(\mathrm{ox})\right]$ & & $8.8(5000)$ & $-61.1(13.5)$ & $-{ }^{d}$ & - & {$[36]$} \\
\hline$\left[\mathrm{Co}^{\mathrm{II}} \mathrm{Cl}(3 \mathrm{G})\right]\left(\mathrm{CF}_{3} \mathrm{SO}_{3}\right)$ & $+12.7(1.2)$ & $24(1500)$ & $\begin{array}{c}-56.8(15.5) \\
+94.4(22.7) \\
+16.9(1.3)\end{array}$ & $\begin{array}{l}12946 \\
\mathbf{8 0 1 8}^{\mathrm{c}} \\
2008^{\mathrm{c}}\end{array}$ & $\begin{array}{c}126205 \\
-\end{array}$ & $\begin{array}{c}\text { This } \\
\text { work } \\
\text { [32] }\end{array}$ \\
\hline$c i s-\left[\mathrm{Co}^{\mathrm{II}}(\mathrm{dmphen})_{2}(\mathrm{NCS})_{2}\right]$ & $+98(8.4)^{\mathrm{a}}$ & $18.1(2500)$ & $+146(27.0)$ & $-{ }^{d}$ & - & {$[69]$} \\
\hline$\left[\mathrm{Co}{ }^{\mathrm{II}}(\mu-\mathrm{L} 5)(\mu-\mathrm{OAc}) \mathrm{Y}\left(\mathrm{NO}_{3}\right)_{2}\right]$ & $+41.7(1.3)$ & $15.7(1000)$ & $\begin{array}{c}+54.5 \\
(10.3)^{\mathrm{b}}\end{array}$ & $-{ }^{d}$ & 114.7 & {$[70]$} \\
\hline $\mathrm{K}\left[\mathrm{Co}^{\mathrm{II}}\left(\mathrm{N}\left[\mathrm{CH}_{2} \mathrm{C}(\mathrm{O}) \mathrm{NCMe}_{3}\right]_{3}\right)\right]$ & $+16(0.0)$ & $8.7(1500)$ & $+36.9(0.05)$ & $-{ }^{c}$ & - & {$[32]$} \\
\hline$\left[\mathrm{Co}^{\mathrm{II}}(\mathrm{abpt})_{2}(\mathrm{tcm})_{2}\right]$ & $+48(13)$ & $59.9(3000)$ & $+53.7(15.6)$ & $-{ }^{d}$ & - & {$[73]$} \\
\hline$\left[\mathrm{Co}^{\mathrm{II}}(\mathrm{acac})_{2}\left(\mathrm{H}_{2} \mathrm{O}\right)_{2}\right]$ & $+57(17.7)$ & - & $\begin{array}{r}+90.1(13.4) \\
+\mathbf{6 3 . 4}(9.5)\end{array}$ & $6081017^{\mathrm{c}}$ & $186 \mathbf{1 3 1}$ & [74] \\
\hline$\left[\mathrm{Co}^{\mathrm{II}} \mathrm{L} 9 \mathrm{Cl}_{2}(\mathrm{MeCN})\right]$ & +15.6 & $10.3(2500)$ & $+20.35(3.6)$ & $2770^{\mathrm{c}}$ & 42.6 & [64] \\
\hline$\left[\mathrm{Co}^{\mathrm{II}} \mathrm{L} 9 \mathrm{Br}_{2}(\mathrm{MeCN})\right]$ & +11.2 & $8.2(2500)$ & $+18.5(4.4)$ & $2644^{c}$ & 40.1 & {$[64]$} \\
\hline$\left[(\mathrm{cAAC})_{2} \mathrm{Fe}^{\mathrm{I}} \mathrm{Cl}\right]$ & $\begin{array}{l}+20.4 \\
(0.2)^{\mathrm{a}}\end{array}$ & $22.4(500)$ & $\begin{array}{c}+36.3(3.8) \\
+\mathbf{1 6 . 2 ( 1 . 0 )}\end{array}$ & $6301787^{c}$ & 76.927 & {$[48]$} \\
\hline
\end{tabular}

a) Non-Kramers system (energy of the third state although the first two states are non-degenerate), b) Truncated models in the calculations c) calculations done with Molcas program (CASSCF/CASPT2), d) calculations done with Orca program (CASSCF/NEVPT2)

The occurrence of SMM behavior with large positive D values is less common and requires halfinteger $\mathrm{S}$ values. Therefore, high-spin $\mathrm{d}^{7}$ and $\mathrm{d}^{3}$ electronic configurations appear to be very promising for achieving mononuclear SMM complexes with moderate positive D values. Recently, some of us have studied the mechanism of the spin relaxation of easy plane systems based on $\mathrm{Co}^{\mathrm{II}}$ centers with large magnetic anisotropy, showing basically the existence of two relaxation mechanisms: a direct term induced by the hyperfine interaction $\left(\mathrm{Co}^{\mathrm{II}}\right.$ has $\left.\mathrm{I}=7 / 2\right)$ which dominates at low temperatures and a Raman term predominant for temperatures above $4 \mathrm{~K}$. Strong nuclear spin-phonon interactions allow spin relaxation through phonon-induced transitions between states differing in their nuclear spin state only, thus breaking the selection rule $\Delta m_{I}=0$ that applies for the hyperfine interaction when nuclear spins are not coupled to phonons. It is worth noting that Orbach processes, which are commonly employed to explain the relaxation in easy axis systems, should not be used to explain spin relaxation in easy plane systems due to the lack of low-lying excited states at energies close to the energy barriers fitted using the experimental data (around $20 \mathrm{~cm}^{-1}$ ).[74] 


\section{Rationalization of the Magnetic Anisotropy of Mononuclear Lanthanide SMM}

Lanthanide complexes are difficult to treat because their electronic repulsion terms are predominant, the ground state wave function has a large multireference character, and there are also major spinorbit effects. These features rule out the straightforward use of molecular orbitals to understand the magnetic properties, as was possible in mononuclear first-row transition metal complexes (see section 3), where a simple orbital picture can explain the large anisotropy present in some systems. Some qualitative attempts have been made using simple models based on the reduction of the electronic repulsion between the metal and the ligands. Analysis of the shape (prolate and oblate) of the electron density of the ground state of the lanthanide[15, 88] together with the spatial distribution of the ligands, allows us to make some predictions. For instance, Chilton et al. were able to synthesize two Dy ${ }^{\text {III }}$ complexes showing SMM behavior that corroborated the predictions of the prolate/oblate concept to determine the magnetization axis.[89] Furthermore, some crystal-field models have been used to predict the SMM of mononuclear lanthanide and actinide complexes.[21, 90, 91] However, these magnetic properties are extremely sensitive to small changes in the structure of the complexes, as shown by the experimental and theoretical study by Sessoli and coworkers,[9294] who reported strong influence of the rotation of the hydrogen atoms in the water ligands in mononuclear Dy ${ }^{\mathrm{III}}$ complexes on their SMM behavior. Therefore, simple qualitative models are not suitable for seeking explanations of important changes in magnetic properties for complexes in which the symmetry of the coordination mode and ligands remains almost unaltered.

Again, as in transition metal complexes, CASSCF+RASSI calculations provide useful information. The experimental magnetic behavior of a set of previously published lanthanide complexes has been analyzed through the information extracted from theoretical calculations. Theoretical methods have been extensively used in the study of lanthanides to determine the degree of axiality in the

complexes reported. However, experimental approaches (single-crystal measures or EPR X-band spectroscopy) have not often been used to test the accuracy of the theoretical approaches. 
Previously, we reported a theoretical study based on mononuclear Dy ${ }^{\mathrm{III}}$ complexes[95], the most prolific family of lanthanide mononuclear SMM complexes (see Table 5) due to their large J value $(15 / 2)$ with Kramers doublet as ground state which favors a large magnetic anisotropy compared with those cations with integer $\mathrm{m}_{\mathrm{J}}$ values (i.e. $\mathrm{Tb}^{\mathrm{III}}$ or $\mathrm{Ho}^{\mathrm{III}}$ centers). We performed a comparison between experimental ac susceptibility data and data obtained from CASSCF+RASSI calculations ( $g$ tensor components and excitation energies). The study focused on the methodology and the necessary conditions for the presence (or suppression) of SMM behavior in mononuclear Dy ${ }^{\text {III }}$ compounds. Considering SMM behavior as a criterion (Table 5 shows the experimental information on the Dy ${ }^{\mathrm{III}}$ mononuclear complexes considered), we were able to classify the Dy ${ }^{\mathrm{III}}$ complexes into three groups: (i) those showing zero-field SMM (determination of a maximum of the $\chi$ ' from ac measurements); (ii) systems which, under a static field (reduction of tunneling effects), show fieldinduced SMM behavior; and (iii) complexes which even in the presence of static fields do not show SMM behavior. It is worth noting that, in some cases, the sample was diluted to diminish magnetic dipolar interactions between neighboring complexes and thus facilitate identification of the barrier to the reversal of magnetization. The calculated $g$ factors of the ground state and energies of the

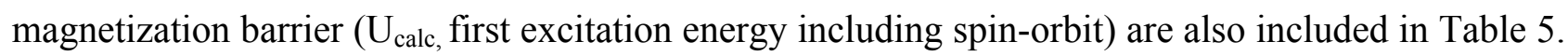
It is worth noting that the spin relaxation mechanism through the first excited state is commonly accepted, but in some cases, as in the $\mathrm{Dy}_{4}$ and $\mathrm{Dy} \mathrm{y}_{5}$ complexes with very high barriers (around 800 K) mentioned above, the first excited state has almost the same direction of the magnetic moment as the ground state. In this way, the relaxation occurs through the next excited state, leading to a higher energy barrier.[16] However, in the mononuclear Dy ${ }^{\mathrm{III}}$ complexes reported in Table 5, the direction of the magnetic moment changes from the ground to the first excited state; therefore, the spin relaxation must occur through the first excited state. 
Table 5. Mononuclear lanthanide complexes studied with post Hartree-Fock methods, indicating whether each one is a zero-field SMM, a field-induced SMM or not an SMM, together with the experimental magnetic anisotropy barrier $\left(\mathrm{U}_{\mathrm{eff}}\right.$, in $\left.\mathrm{cm}^{-1}\right)$ and the values calculated at the $\mathrm{CASSCF}+\mathrm{RASSI}$ level for the barrier $\left(\mathrm{U}_{\text {calc }}\right.$, in $\mathrm{cm}^{-1}$, first excitation energy $\delta \mathrm{E}_{1}$ including spin-orbit effects), the $g$ components and $g_{x y}=\left(g_{x}{ }^{2}+g_{y}{ }^{2}\right)^{1 / 2}$.

\begin{tabular}{|c|c|c|c|c|c|c|c|c|c|}
\hline Complexes & $\begin{array}{c}\text { SMM } \\
\mathrm{H}=0\end{array}$ & $\begin{array}{c}\text { SMM } \\
\mathrm{H} \neq 0\end{array}$ & $\mathrm{U}_{\text {eff }}$ & $\mathrm{U}_{\text {cal }}$ & $\mathrm{g}_{\mathrm{z}}$ & $\mathrm{g}_{\mathrm{y}}$ & $g_{x}$ & $g_{x y}$ & ref. \\
\hline$\left[\mathrm{Dy}(\mathrm{dpq})(\mathrm{acac})_{3}\right]$ & yes & - & 94 & 120.4 & 19.237 & 0.014 & 0.004 & 0.015 & {$[96]$} \\
\hline$\left[\mathrm{Dy}(\mathrm{dppz})(\mathrm{acac})_{3}\right] \cdot \mathrm{CH}_{3} \mathrm{OH}$ & yes & - & 130 & 146.2 & 19.368 & 0.009 & 0.005 & 0.010 & {$[96]$} \\
\hline$\left[\mathrm{Dy}(\mathrm{acac})_{3}\left(\mathrm{H}_{2} \mathrm{O}\right)_{2}\right]$ & yes & - & 45.9 & 151.9 & 19.457 & 0.007 & 0.005 & 0.009 & [97] \\
\hline$\left[\right.$ Dy $($ phen $\left.)(\text { acac })_{3}\right]$ & yes & - & 44.4 & 135.8 & 19.389 & 0.007 & 0.004 & 0.008 & {$[98]$} \\
\hline$[\mathrm{Dy}(\mathrm{Pc})(\mathrm{TClPP})]$ & yes & - & 16 & - & - & - & - & - & {$[99]$} \\
\hline$\left[\mathrm{Dy}(\mathrm{bpy})(\mathrm{TTA})_{3}\right]$ & yes & - & 40 & 142.6 & 19.595 & 0.006 & 0.003 & 0.007 & {$[100]$} \\
\hline$\left[\mathrm{Dy}(\right.$ phen $\left.)(\mathrm{TTA})_{3}\right]$ & yes & - & 59 & 126.3 & 19.511 & 0.009 & 0.005 & 0.010 & {$[100]$} \\
\hline$\left[\mathrm{Dy}(\mathrm{FTA})_{3} \mathrm{~L} 10\right]$ & yes & - & 37.8 & 67.2 & 19.243 & 0.326 & 0.158 & 0.362 & [101] \\
\hline$\left[\mathrm{Dy}\left(\mathrm{COT},{ }_{2} \operatorname{Li}(\mathrm{THF})(\mathrm{DME})\right]\right.$ & yes & - & 17 & 45.6 & 16.896 & 0.071 & 0.024 & 0.075 & [102] \\
\hline$\left[\mathrm{Dy}\left(\mathrm{paaH}^{*}\right)_{2}\left(\mathrm{H}_{2} \mathrm{O}\right)_{4}\right]$ & yes & - & 124 & 243.5 & 19.652 & 0.001 & 0.001 & 0.001 & {$[89]$} \\
\hline$[\mathrm{K}(18 \mathrm{C} 6)]\left[\mathrm{Dy}(\mathrm{COT})_{2}\right]$ & yes & - & 7.6 & 22.3 & 12.644 & 0.145 & 0.062 & & [103] \\
\hline$\left[\mathrm{Zn}_{2} \mathrm{DyL} 11_{2}(\mathrm{MeOH})\right] \mathrm{NO}_{3} \cdot 3 \mathrm{MeOH} \cdot \mathrm{H}_{2} \mathrm{O}$ & yes & - & 305 & 289.9 & 19.870 & 0.000 & 0.000 & & [104] \\
\hline$\left[\mathrm{Dy}\left(\mathrm{COT}^{\prime \prime}\right)_{2}\right] \mathrm{Li}(\mathrm{DME})_{3}$ & yes & - & 17.4 & & 1.354 & 10.629 & 10.667 & & {$[105]$} \\
\hline$\left[\operatorname{Dy}(\mathrm{TTA})_{3}(\mathrm{~L} 12)\right] \cdot \mathrm{C}_{6} \mathrm{H}_{14}$ & yes & - & 27.8 & - & 19.5 & 0.0 & 0.0 & & {$[106]$} \\
\hline$\left[\mathrm{Dy}\left(\mathrm{paaH}^{*}\right)_{2}\left(\mathrm{NO}_{3}\right)_{2}(\mathrm{MeOH})\right]$ & no & $2000 \mathrm{Oe}$ & 44 & 111.0 & 19.592 & 0.017 & 0.013 & 0.021 & {$[89]$} \\
\hline$\left[\mathrm{Dy}(9 \mathrm{Accm})_{2}\left(\mathrm{NO}_{3}\right)(\mathrm{dmf})\right]$ & no & $1000 \mathrm{Oe}$ & 16 & 188.9 & 19.482 & 0.051 & 0.027 & 0.058 & [107] \\
\hline$\left[\mathrm{Dy}(\mathrm{NTA})_{3} \mathrm{~L} 13\right]^{\mathrm{a}}$ & no & $2000 \mathrm{Oe}$ & 21.1 & 93.0 & 19.258 & 0.067 & 0.023 & 0.071 & [108] \\
\hline$\left[\mathrm{Dy}\left(\mathrm{Pc}\left(\mathrm{a}-\mathrm{OC}_{5} \mathrm{H}_{11}\right)_{4}\right)(\mathrm{TClPP})\right]$ & no & $2000 \mathrm{Oe}$ & 30 & - & - & - & - & - & {$[99]$} \\
\hline$\left[\mathrm{DyH}\left(\mathrm{Pc}\left(\mathrm{a}-\mathrm{OC}_{5} \mathrm{H}_{11}\right)_{4}\right)(\mathrm{TClPP})\right]$ & no & $2000 \mathrm{Oe}$ & 40 & - & - & - & - & - & {$[99]$} \\
\hline$\left[\mathrm{Dy}\left(\mathrm{H}_{2} \mathrm{~L} 14\right)\left(\mathrm{NO}_{3}\right)_{3}\right] \cdot 2 \mathrm{CH}_{3} \mathrm{OH}$ & no & $1000 \mathrm{Oe}$ & 22.2 & 80.4 & 18.988 & 0.654 & 0.221 & 0.690 & [109] \\
\hline$[\mathrm{K}(\mathrm{DME})(18 \mathrm{C} 6)]\left[\mathrm{Dy}(\mathrm{tmtaa})_{2}\right]$ & no & $1000 \mathrm{Oe}^{\mathrm{b}}$ & 19.7 & 77.3 & 16.086 & 0.662 & 0.625 & 0.910 & [110] \\
\hline$\left[\mathrm{K}(\mathrm{DME})_{2}\right]\left[\mathrm{Dy}(\mathrm{tmtaa})_{2}\right]$ & no & $1000 \mathrm{Oe}^{\mathrm{b}}$ & 24.0 & 75.3 & 16.853 & 0.571 & 0.488 & 0.751 & {$[110]$} \\
\hline$\left[\mathrm{Dy}(\mathrm{TTA})_{3}(\mathrm{~L} 15)\right]$ & no & $2000 \mathrm{Oe}$ & 28.5 & 109.1 & 19.685 & 0.025 & 0.011 & 0.027 & [111] \\
\hline$\left[\mathrm{Dy}\left(\mathrm{H}_{2} \mathrm{BPz}^{\mathrm{Me} 2}{ }_{2}\right)_{3}\right]$ & no & $1000 \mathrm{Oe}^{\mathrm{b}}$ & 17 & 58.7 & 19.684 & 0.027 & 0.019 & 0.033 & {$[22]$} \\
\hline$\left[\mathrm{Zn}_{2} \mathrm{DyL} 11_{2}\right] \mathrm{NO}_{3} \cdot \mathrm{H}_{2} \mathrm{O}$ & no & $1200 \mathrm{Oe}$ & $\mathrm{n}=4.83$ & 294.8 & 19.763 & 0.014 & 0.012 & & [104] \\
\hline$\left[\mathrm{Dy}\left(\mathrm{H}_{3} \mathrm{~L} 16\right)_{2}\right]\left(\mathrm{NO}_{3}\right) \cdot(\mathrm{EtOH}) \cdot 8\left(\mathrm{H}_{2} \mathrm{O}\right)$ & no & $200 \mathrm{Oe}^{\mathrm{b}}$ & 42.0 & 106.2 & 18.769 & 0.045 & 0.024 & & [112] \\
\hline$\left[\mathrm{Dy}\left(\mathrm{AlMe}_{4}\right)_{3}\right]$ & no & $1000 \mathrm{Oe}^{\mathrm{b}}$ & 10 & 10.9 & 15.73 & 3.04 & 0.10 & & [113] \\
\hline$\left[\mathrm{Dy}(\mathrm{NTA})_{3} \mathrm{~L} 13\right]^{\mathrm{a}}$ & no & - & - & 40.8 & 17.932 & 0.509 & 0.223 & 0.556 & [108] \\
\hline$\left[\mathrm{Dy}(\mathrm{phen})_{2}\left(\mathrm{NO}_{3}\right)_{2}(\mathrm{acac})\right]$ & no & - & - & 106.6 & 18.951 & 0.477 & 0.211 & 0.522 & {$[98]$} \\
\hline$\left[\mathrm{Dy}(\mathrm{hfac})_{3}(\mathrm{~L} 17)_{2}\right]$ & no & - & & - & - & - & - & - & [114] \\
\hline$\left[\mathrm{Na}\left[\mathrm{Dy}(\mathrm{DOTA})\left(\mathrm{H}_{2} \mathrm{O}\right)\right]\right] \cdot 4 \mathrm{H}_{2} \mathrm{O}$ & & & & & 18.6 & 0.9 & 0.2 & & {$[93]$} \\
\hline$\left[\mathrm{Yb}\left(\mathrm{H}_{3} \mathrm{~L} 18\right)_{2}\right] \mathrm{Cl}_{3} \cdot 5 \mathrm{CH}_{3} \mathrm{OH} \cdot 2 \mathrm{H}_{2} \mathrm{O}$ & no & $400 \mathrm{Oe}$ & $\mathrm{n}=2.37$ & 187.9 & 1.763 & 2.694 & 3.210 & & [115] \\
\hline $\mathrm{Na}\left[\operatorname{TbDOTA}\left(\mathrm{H}_{2} \mathrm{O}\right)\right] \cdot 4 \mathrm{H}_{2} \mathrm{O}$ & no & - & - & & 12.7 & 2.1 & 0.5 & & {$[92]$} \\
\hline $\mathrm{Na}\left[\mathrm{HoDOTA}\left(\mathrm{H}_{2} \mathrm{O}\right)\right] \cdot 4 \mathrm{H}_{2} \mathrm{O}$ & no & - & - & & 6.2 & 3.3 & 1.3 & & [92] \\
\hline$[\mathrm{K}(18 \mathrm{C} 6)]\left[\operatorname{Er}(\mathrm{COT})_{2}\right]$ & yes & - & 199 & 175.3 & 17.959 & 0.000 & 0.000 & & [103] \\
\hline
\end{tabular}




\begin{tabular}{lcccccccc}
\hline $\mathrm{Na}\left[\operatorname{ErDOTA}\left(\mathrm{H}_{2} \mathrm{O}\right)\right] \cdot 4 \mathrm{H}_{2} \mathrm{O}$ & no & $1000 \mathrm{Oe}$ & 27.1 & 19.8 & 10.9 & 2.8 & 1.8 & {$[92]$} \\
$\mathrm{Na}\left[\operatorname{TmDOTA}\left(\mathrm{H}_{2} \mathrm{O}\right)\right] \cdot 4 \mathrm{H}_{2} \mathrm{O}$ & no & - & - & & 12.2 & 1.02 & 0.95 & {$[92]$} \\
$\mathrm{Na}\left[\mathrm{YbDOTA}\left(\mathrm{H}_{2} \mathrm{O}\right)\right] \cdot 4 \mathrm{H}_{2} \mathrm{O}$ & no & $1000 \mathrm{Oe}$ & 20.2 & 197.2 & 6.8 & 1.0 & 0.1 & {$[92]$} \\
\hline
\end{tabular}

a) two polymorphs of the same complex, b) diluted sample

$\underline{\text { acac }}=$ acetylacetonate; $\underline{\mathrm{dpq}}=$ pyrazino[2,3-f][1,10]phenanthroline; $\underline{\mathrm{dppz}}=$ dipyrido[3,2-a:2',3'-c]phenazine; phen $=$ 1,10-phenanthroline; $\underline{\mathrm{Pc}}=$ unsubstituted phthalocyaninate; $\underline{\mathrm{TCIPP}}=$ meso-tetrakis-(4-chlorophenyl)porphyrinate; $\underline{\mathrm{bpy}}=$

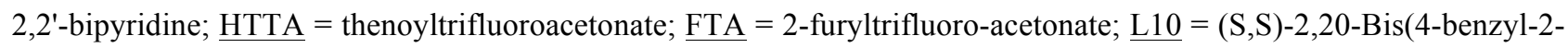
oxazoline); COT $^{\prime}=1,4$-bis(trimethylsilyl)cyclooctatetraenyl dianion; paaH* $^{*}=\mathrm{N}$-(2-Pyridyl)-ketoacetamide (the neutral zwitterionic form); $\underline{18 \mathrm{C} 6}=18$-crown-6; $\underline{\mathrm{COT}}=$ cyclooctatetraene; $\underline{\mathrm{L} 11}=2,2$ ',2' '-(( (nitrilotris(ethane-2,1diyl))tris(azanediyl))tris(methylene))tris-(4-bromophenol); $\quad \underline{\mathrm{L} 12}=4,5$-bis(propylthio)-tetrathiafulvalene-2-(2pyridyl)benzimidazole-methyl-2-pyridine; $\underline{9 \text { Accm }}=1,7$-di-9-anthracene-1,6-heptadiene-3,5-dione; $\quad \underline{\text { NTA }}=$ naphthyltrifluoroacetonate; $\underline{\mathrm{L} 13}=(1 \mathrm{R}, 2 \mathrm{R})-1,2$-diphenylethane-1,2-diamine; $\underline{\mathrm{Pc}(\mathrm{a}-\mathrm{OC}} \underline{5}_{5} \underline{\mathrm{H}}_{11} \underline{4}_{4}=1,8$, 15,22-tetrakis(3pentyloxy)phthalocyaninate; $\underline{\mathrm{H}}_{2} \underline{\mathrm{L} 14}=N, N$ ', $N$ ',-trimethyl- $N, N$ ' '-bis(2-hydroxy-3-methoxy-5-methylbenzyl) diethylene triamine; $\underline{\mathrm{H}}_{2} \underline{\operatorname{tmtaa}}=6,8,15,17$-tetramethyldibenzotetraaza[14]annulene; $\underline{\mathrm{L} 15}=4,5$-pinene bipyridine; $\underline{\mathrm{H}}_{3} \underline{\mathrm{BPz}} \underline{\mathrm{Me}}_{2}=$ dihydrobis-(dimethylpyrazolyl)borate; $\underline{\mathrm{H}}_{4} \underline{\mathrm{L} 16}=2,2^{\prime}$-[[(2-aminoethyl)imino]bis[2,1-ethanediyl-nitriloethylidyne ] bis-2hydroxy-benzoic acid; $\underline{\mathrm{Hhfac}}=1,1,1,5,5,5$-hexafluoroacetylacetonate; $\underline{\mathrm{L} 17}=$ tetrathiafulvalene-amido-2-pyridine-Noxide; $\underline{\mathrm{H}}_{4} \underline{\mathrm{DOTA}}=1,4,7,10$-tetraazacyclododecane $\mathrm{N}, \mathrm{N}^{\prime}, \mathrm{N}^{\prime},{ }^{\prime},{ }^{\prime}$, -tetraacetic acid; $\underline{\mathrm{H}}_{3} \underline{\mathrm{L} 18}=\operatorname{tris}(((2-\mathrm{hyd}$ droxy-3methoxybenzyl)amino)ethyl)-amine

From the results calculated for the Dy ${ }^{\text {III }}$ complexes, we can see that the ground state is always markedly axial, with $\mathrm{g}_{\mathrm{z}}$ values ranging from 16 to almost 20 . The magnetic anisotropy barrier was estimated assuming that relaxation will occur through the first excited state $\left(\mathrm{U}_{\mathrm{cal}}\right.$ values correspond to the first excitation energy calculated after the inclusion of the spin-orbit coupling). But a comparison between the experimentally determined $\mathrm{U}_{\mathrm{eff}}$ energy barrier and the corresponding calculated $\mathrm{U}_{\mathrm{cal}}$ value shows that there is no proper correlation between these parameters. We considered that the origin of this discrepancy may be the existence of other effects (for example, tunneling in the ground state or induced by dipolar coupling with neighboring molecules or vibronic coupling) which are important for the experimental $U_{\text {eff }}$ values but were not considered in the $U_{\text {cal }}$ values. In our previous study of $\mathrm{Dy}^{\mathrm{III}}$ complexes, we focused on tunneling within the Kramers doublet ground state. We considered the values of the $\mathrm{g}_{\mathrm{x}}$ and $\mathrm{g}_{\mathrm{y}}$ components which describe this ground state as parameters to characterize the magnitude of the tunneling, at least qualitatively. It can be observed that complexes which present zero-field $S M M$ behavior (see Table 5) show low $\mathrm{g}_{\mathrm{xy}}$ values $(<0.08)$, while field-induced SMMs span a broad range of values $(0.027$ to 0.910$)$, and finally, complexes that do not show SMM behavior present high $g_{x y}(>0.5)$. These Hamiltonian 
terms including $g_{x}$ and $g_{y}$ terms mix the states of the ground doublet. The role of transverse anisotropy has already been associated with the importance of the tunneling effects in SMMs.[116] As seen previously, the $g_{x}$ and $g_{y}$ values (or $g_{x y}$ ) calculated at the CASSCF+RASSI level can help to classify the Dy ${ }^{\mathrm{III}}$ complexes with respect to their SMM properties. However, it is not easy to make an a priori prediction of their magnitudes. In order to extract more information, we analyzed which requirements are needed on the spin-free states (before applying RASSI to add spin-orbit effects) for the $g_{x}$ and $g_{y}$ values to be small. We found that to obtain a strongly axial ground state after the inclusion of spin-orbit coupling, a very low spin-free first excited state ( $\Delta \mathrm{E}_{1}$ energy) is needed while the second one ( $\Delta \mathrm{E}_{2}$ energy) must be as high as possible (see below). In such cases, the final ground doublet will mainly be composed of the ground and first excited spin-free states, after the mixing induced by the spin-orbit operator. We stress that for transition metal complexes, the main requirement is a small $\Delta \mathrm{E}_{1}$ value (first excitation energy calculated without spin-orbit effects) as clearly shown in section 3 .

For the Dy ${ }^{\mathrm{III}}$ complexes, we propose the $\left(\Delta \mathrm{E}_{2}-\Delta \mathrm{E}_{1}\right) / \Delta \mathrm{E}_{1}$ parameter given in Table 6 as a figure of merit: high $\left(\Delta \mathrm{E}_{2}-\Delta \mathrm{E}_{1}\right) / \Delta \mathrm{E}_{1}$ parameters should correlate with more axial $g$ tensors and consequently, with SMM behavior. Table 6 shows two different patterns: (i) systems with small $\Delta \mathrm{E}_{1}$ and large $\Delta \mathrm{E}_{2}$ values usually show zero-field SMM behavior and (ii) systems with small $\Delta \mathrm{E}_{1}$ and also relatively small $\Delta \mathrm{E}_{2}$ values are usually field-induced SMM (sandwich complexes).

The electrostatic metal-ligand interactions are a key factor affecting the electrostatic potential that will interact with the $f$ electrons of the Dy ${ }^{\mathrm{III}}$ ion. By studying the electrostatic potential, we were able to analyze how the electron density of the Dy ${ }^{\mathrm{III}}$ centers can be arranged to reduce the electron repulsion.[95] The idea is similar to the one previously considered by Rinehart et al. with the prolate/oblate model[88] and also recently described by Chilton et al.[117] In order to improve the representation of the anisotropy of the f electron density of the Dy ${ }^{\mathrm{III}}$ centers $\left(4 \mathrm{f}^{9}\right)$, we considered only the beta $4 \mathrm{f}$ electrons (since the other seven alpha electrons produce an isotropic spherical distribution). Therefore, we used this partial electron density calculated at spin-free CASSCF states 
(corresponding to the two beta electrons of the Dy ${ }^{\mathrm{III}}$ centers) as magnitude to discuss the magnetic anisotropy.[95] The mixing of such spin-free states induced by spin-orbit coupling will result in the ground state of the system which will determine the magnetic properties. Thus, the energy differences between ground and excited states (Table 6) are crucial to determine the mixing between these states when the spin-orbit effects are included. It is worth mentioning that the anisotropic shape of the electron density of this spin-orbit ground state cannot be easily visualized because there is no distinction between alpha and beta electrons. Thus, the whole density of the nine $\mathrm{f}$ electrons has to be plotted, and this is less instructive for the visualization of the magnetic anisotropy. Therefore, the representation of the partial electron density calculated at spin-free level allows a qualitative estimation of the shape of the partial electron density (eighth and ninth electrons) of the Dy ${ }^{\text {III }}$ centers which causes the magnetic anisotropy.

Table 6. Some mononuclear Dy ${ }^{\mathrm{III}}$ complexes, indicating whether each one is a zero-field SMM, a field-induced SMM or not an SMM, the calculated CASSCF (spin-free) first and second excitation energies $\left(\Delta \mathrm{E}_{1}\right.$ and $\Delta \mathrm{E}_{2}$, in $\left.\mathrm{cm}^{-1}\right)$ and the $\left(\Delta \mathrm{E}_{2}-\Delta \mathrm{E}_{1}\right) / \Delta \mathrm{E}_{1}$ parameter.

\begin{tabular}{|c|c|c|c|c|c|}
\hline Complexes & $\begin{array}{c}\text { SMM } \\
\mathrm{H}=0\end{array}$ & $\begin{array}{l}\text { SMM } \\
\mathrm{H} \neq 0\end{array}$ & $\Delta \mathrm{E}_{1}$ & $\Delta \mathrm{E}_{2}$ & $\left(\Delta \mathrm{E}_{2}-\Delta \mathrm{E}_{1}\right) / \Delta \mathrm{E}_{1}$ \\
\hline$\left[\mathrm{Dy}(\mathrm{dpq})(\mathrm{acac})_{3}\right]$ & yes & - & 3.9 & 157.1 & 39.3 \\
\hline$\left[\mathrm{Dy}(\mathrm{dppz})(\mathrm{acac})_{3}\right] \cdot \mathrm{CH}_{3} \mathrm{OH}$ & yes & - & 7.4 & 195.1 & 25.4 \\
\hline$\left[\mathrm{Dy}(\mathrm{acac})_{3}\left(\mathrm{H}_{2} \mathrm{O}\right)_{2}\right]$ & yes & - & 5.1 & 195.0 & 37.2 \\
\hline$\left[\mathrm{Dy}(\mathrm{phen})(\mathrm{acac})_{3}\right]$ & yes & - & 7.3 & 189.8 & 25.0 \\
\hline$\left[\mathrm{Dy}(\mathrm{bpy})(\mathrm{TTA})_{3}\right]$ & yes & - & 8.6 & 139.0 & 15.2 \\
\hline$\left[\mathrm{Dy}(\mathrm{phen})(\mathrm{TTA})_{3}\right]$ & yes & - & 11.0 & 141.7 & 11.9 \\
\hline$\left[\mathrm{Dy}(\mathrm{FTA})_{3} \mathrm{~L} 10\right]$ & yes & - & 41.0 & 98.5 & 1.4 \\
\hline$\left[\mathrm{Dy}\left(\mathrm{COT}{ }^{\prime}\right)_{2} \operatorname{Li}(\mathrm{THF})(\mathrm{DME})\right]$ & yes & - & 2.0 & 39.4 & 18.7 \\
\hline$\left[\mathrm{Dy}\left(\mathrm{paaH}^{*}\right)_{2}\left(\mathrm{H}_{2} \mathrm{O}\right)_{4}\right]$ & yes & - & 8.1 & 356.5 & 44.0 \\
\hline$\left[\mathrm{Dy}\left(\mathrm{paaH}^{*}\right)_{2}\left(\mathrm{NO}_{3}\right)_{2}(\mathrm{MeOH})\right]$ & no & $2000 \mathrm{Oe}$ & 28.9 & 140.5 & 4.9 \\
\hline$\left[\mathrm{Dy}(9 \mathrm{Accm})_{2}\left(\mathrm{NO}_{3}\right)(\mathrm{dmf})\right]$ & no & $1000 \mathrm{Oe}$ & 14.3 & 248.6 & 16.4 \\
\hline$\left[\mathrm{Dy}(\mathrm{NTA})_{3} \mathrm{~L} 13\right]^{\mathrm{a}}$ & no & $2000 \mathrm{Oe}$ & 26.2 & 136.6 & 4.2 \\
\hline$\left[\mathrm{Dy}\left(\mathrm{H}_{2} \mathrm{~L} 14\right)\left(\mathrm{NO}_{3}\right)_{3}\right] \cdot 2 \mathrm{CH}_{3} \mathrm{OH}$ & no & $1000 \mathrm{Oe}^{*}$ & 77.5 & 138.7 & 0.8 \\
\hline$[\mathrm{K}(\mathrm{DME})(18 \mathrm{C} 6)]\left[\mathrm{Dy}(\mathrm{tmtaa})_{2}\right]$ & no & $1000 \mathrm{Oe}^{*}$ & 12.8 & 22.8 & 0.8 \\
\hline$\left[\mathrm{K}(\mathrm{DME})_{2}\right]\left[\mathrm{Dy}(\mathrm{tmtaa})_{2}\right]$ & no & $1000 \mathrm{Oe}^{*}$ & 9.6 & 10.3 & 0.1 \\
\hline$\left[\mathrm{Dy}(\mathrm{TTA})_{3}(\mathrm{~L} 15)\right]$ & no & $2000 \mathrm{Oe}$ & 7.7 & 88.8 & 10.5 \\
\hline$\left[\mathrm{Dy}\left(\mathrm{H}_{2} \mathrm{BPz}_{2}\right)_{3}\right)_{3}$ & no & $1000 \mathrm{Oe}^{*}$ & 2.2 & 69.9 & 30.8 \\
\hline$\left[\mathrm{Dy}(\mathrm{NTA})_{3} \mathrm{~L} 13\right]^{\mathrm{a}}$ & no & - & 45.1 & 109.2 & 1.4 \\
\hline$\left[\mathrm{Dy}(\mathrm{phen})_{2}\left(\mathrm{NO}_{3}\right)_{2}(\mathrm{acac})\right]$ & no & - & 39.6 & 156.8 & 3.0 \\
\hline$\left[\mathrm{Dy}\left(\mathrm{H}_{3} \mathrm{~L} 18\right)_{2}\right]\left(\mathrm{NO}_{3}\right) \cdot(\mathrm{EtOH}) \cdot 8\left(\mathrm{H}_{2} \mathrm{O}\right)$ & no & $200 \mathrm{Oe}^{\mathrm{b}}$ & 5.5 & 182.7 & \\
\hline
\end{tabular}


For a zero-field Dy ${ }^{\mathrm{III}} \mathrm{SMM}$ (i.e. [Dy $\left.(\mathrm{acac})_{3}\left(\mathrm{H}_{2} \mathrm{O}\right)_{2}\right]$ complex), we obtained an axially-compressed shape equivalent to a disc $\left({ }^{6} \mathrm{H}_{15 / 2} \mathrm{~m}_{\mathrm{J}}=15 / 2\right.$ ground state of the Dy ${ }^{\mathrm{III}}$ center, usually called oblate) with its main magnetic anisotropy axis perpendicular to the beta electron density plane. In Figure 3 , this beta electron density is also represented for the first three spin-free excited states. We can now understand better the previous statement that the magnetic anisotropy will be larger if $\Delta \mathrm{E}_{1}$ is small and $\Delta \mathrm{E}_{2}$ is large (the energy differences between the ground state and first and second excited states respectively). In such cases, the spin-orbit coupling mainly has the effect of mixing the first two states with similar electron distribution shape (see Fig. 3); thus, the beta electron density of the spinorbit ground state is mostly a combination of two electron distributions that are similar with small contribution from the third state, whose different shape (see Fig. 3) would reduce the anisotropy.

\section{ground state first excited state second excited state third excited state}

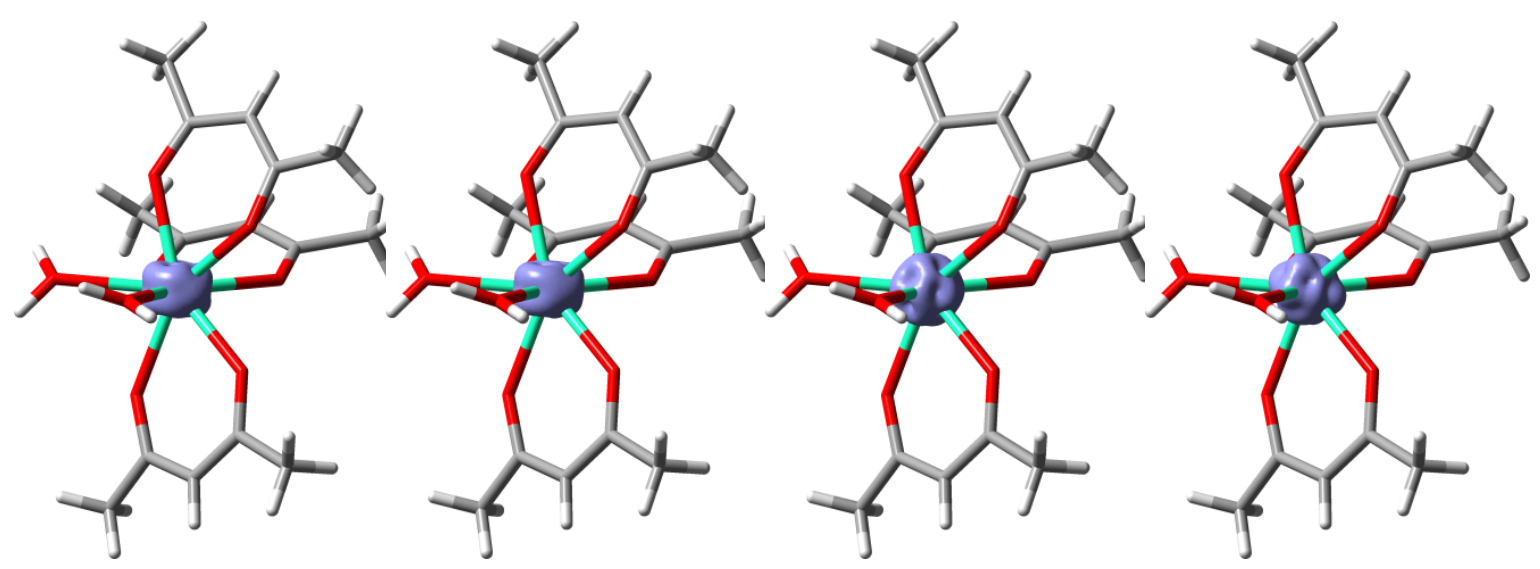

Figure 3. Electron density of the beta electrons of the first four spin-free states calculated as the difference between the total density and the spin density of the seven alpha active electrons in the CASSCF (spin free) for the [Dy $\left.(\operatorname{acac})_{3}\left(\mathrm{H}_{2} \mathrm{O}\right)_{2}\right]$ complex.[95]

To study the influence of the charge of the ligands, we constructed additional model structures based on [Dy(acac $\left.)_{3}\left(\mathrm{H}_{2} \mathrm{O}\right)_{2}\right]$ complex: one with all the ligands replaced by water molecules $\left(8 \mathrm{H}_{2} \mathrm{O}\right.$ model); another replaced by hydroxide ions $\left(8 \mathrm{OH}^{-}\right.$model $)$; another with five water molecules and 3 $\mathrm{OH}^{-}$groups $\left(5 \mathrm{H}_{2} \mathrm{O} / 3 \mathrm{OH}^{-}\right)$; and a $2 \mathrm{H}_{2} \mathrm{O} / 6 \mathrm{OH}^{-}$model.[95] We found that the two homoleptic models (only water or $\mathrm{OH}^{-}$ligands) presented $\mathrm{g}_{\mathrm{x}}$ and $\mathrm{g}_{\mathrm{y}}$ values that were higher than those calculated for the 
original complex (and also had a more isotropic beta density: see Fig. 4 in comparison with Fig. 3), and were therefore unsuitable as SMMs. In contrast, models combining $\mathrm{H}_{2} \mathrm{O}$ and $\mathrm{OH}^{-}$ligands give more axial $g$ factors and more axial compressed beta electron densities, see Fig. 4, similar to those obtained for the $\left[\mathrm{Dy}(\mathrm{acac})_{3}\left(\mathrm{H}_{2} \mathrm{O}\right)_{2}\right]$ complex (Fig. 3).

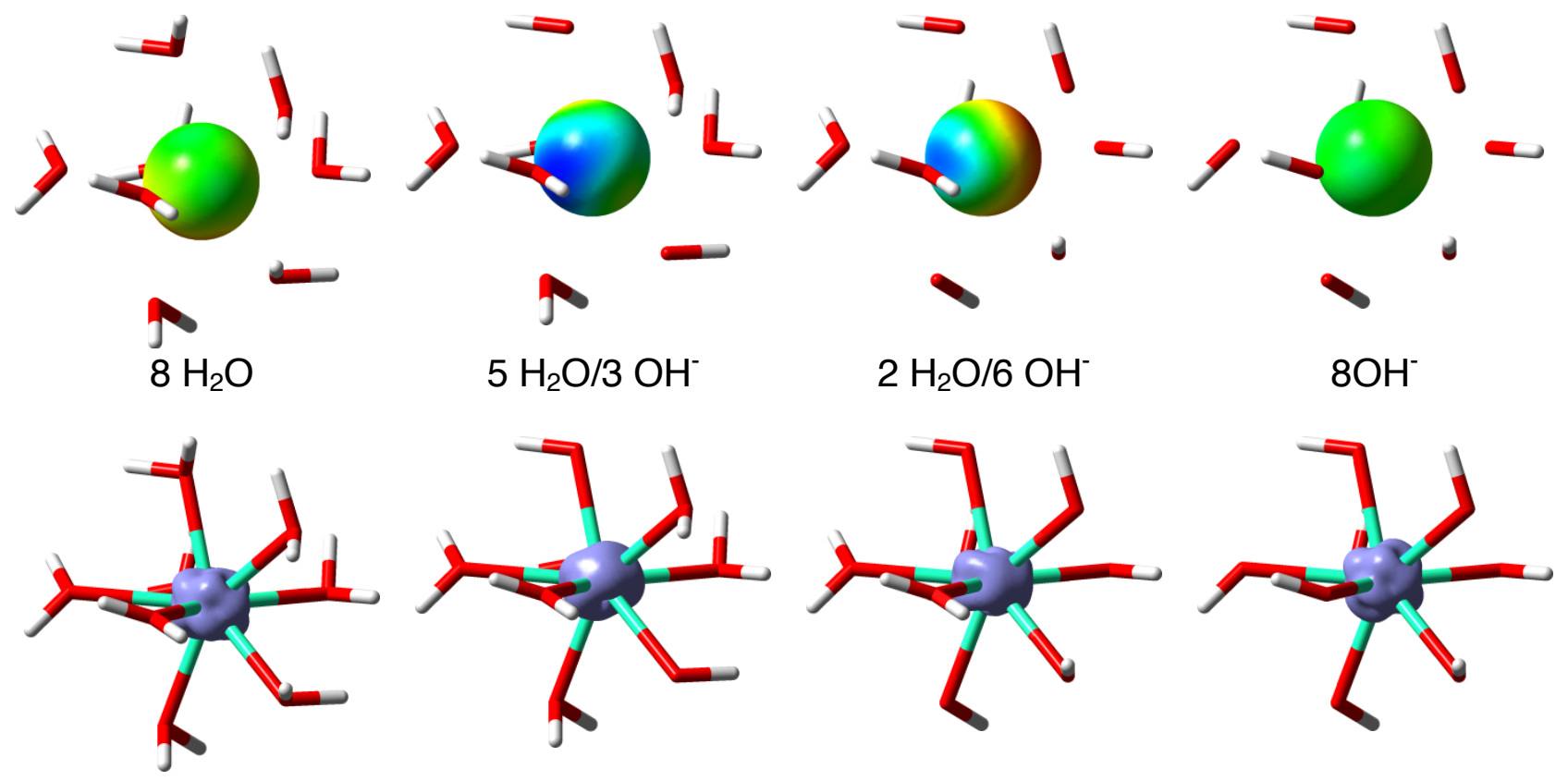

Figure 4: (above) Electrostatic potential projection (a range of 0.09 a.u. was adopted with the limit values in red and blue respectively, to compare systems with different electrostatic potential values) on a sphere of $1 \AA$ of radius centered on the Dy position caused by the ligands fixed for the truncated models of [Dy(acac $\left.)_{3}\left(\mathrm{H}_{2} \mathrm{O}\right)_{2}\right]$. (below) Isosurface of the calculated beta electron density for the ground state of the complexes calculated as the difference between the total density and the spin density of the seven alpha active electrons.[95]

We used DFT calculations to construct electrostatic potential maps of the coordinated ligands at the Dy position and thus to check the role of the metal-ligand electron repulsion.[95] As shown in Figure 4, the homoleptic models (only water or $\mathrm{OH}^{-}$ligands) showed almost isotropic electrostatic potentials, thus confirming the absence of a preferential orientation for the electron density of the Dy ${ }^{\text {III }}$ centers, and consequently the lack of magnetic anisotropy. For the heteroleptic systems (water and $\mathrm{OH}^{-}$ligands), the least negative electrostatic potentials are the regions closest to the water ligands (blue regions in Fig. 4). Thus, the high and low islands of the electrostatic potential are located on opposite sides of the sphere. The metal beta electron density is located between them in 
the direction of the minimum electrostatic potential of the sphere (blue regions in Fig. 4 for the complexes with $\mathrm{H}_{2} \mathrm{O}$ and $\mathrm{OH}^{-}$ligands simultaneously) in order to reduce the electronic repulsion by averting proximity with the more negatively charged ligands. It is worth bearing in mind that the magnetic anisotropy axis will be perpendicular to the density disc. With this very intuitive idea, we can look for the plane containing the ligands that results in the lowest electrostatic potential (for the [Dy(acac $\left.)_{3}\left(\mathrm{H}_{2} \mathrm{O}\right)_{2}\right]$ complex, the plane containing the two water molecules) and we can predict that the magnetization easy axis is perpendicular to that plane.

Differences in first coordination sphere distances can significantly modify the role of the electrostatic potential of the ligands. Thus, if one of metal-ligand distances is significantly shorter than the others, in order to reduce the metal-ligand electronic repulsion, the electron density disc should be placed perpendicular to this short metal-ligand bond and consequently, the direction of the magnetic moment will coincide with this shortest bond. Thus, using these two simple criteria (charge of the ligands and metal-ligand distances) the direction of the magnetic moment can be predicted for mononuclear complexes as well as each individual contribution of the lanthanide centers in polynuclear complexes.

Finally, we performed a screening using CASSCF+RASSI method (MOLCAS code)[118] of the magnetic anisotropy of Dy ${ }^{\text {III }}$ complexes with 41 different coordination modes (see Fig. 5). In order to simplify the models, we assumed that the complexes are neutral. Thus, we included three hydroxo groups as ligands (only two for the coordination number 2, and consequently with charge $+1)$ and the other positions are occupied by water molecules. As previously noticed, the magnetic properties are very sensitive to changes in the proton distribution,[92-94] thus, these results should be careful analyzed in such aspect.[119] The Dy-O bond distances were fixed at $2.25 \AA$, and the coordination polyhedra are perfectly regular. The criterion for the choice of the polyhedron for some coordination numbers was the more abundant presence in the Dy ${ }^{\mathrm{III}}$ structures reported in the Cambridge Structural Database (for instance, for coordination number 9 the capped square antiprism polyhedron).[120] 

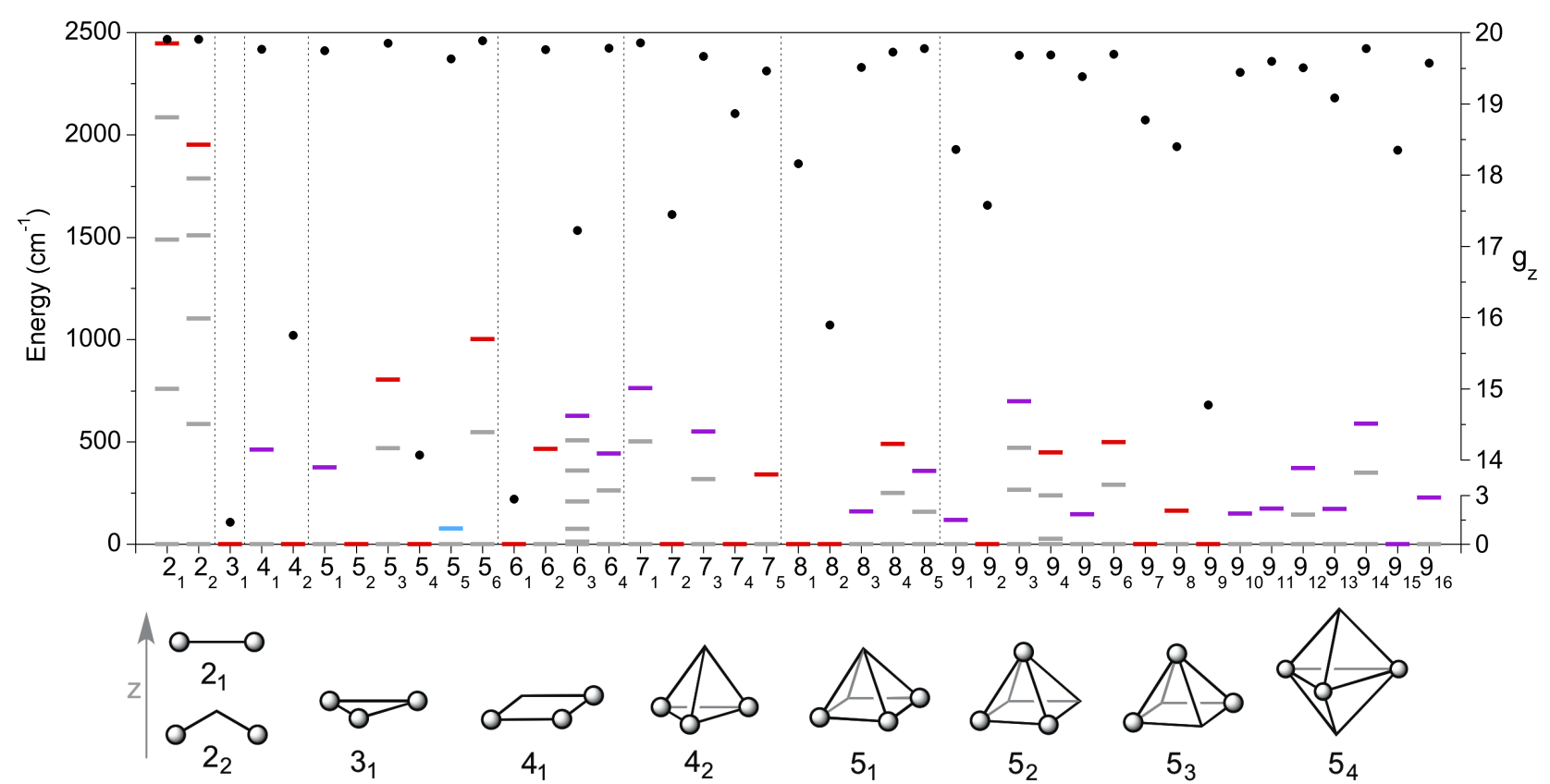

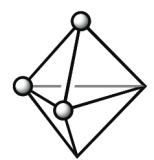

$5_{5}$

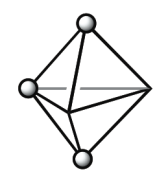

$5_{6}$

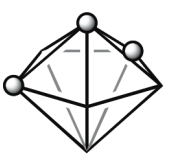

$7_{3}$

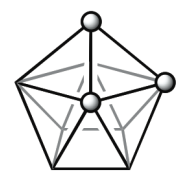

$9_{1}$

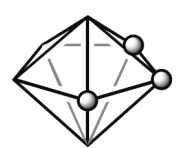

74

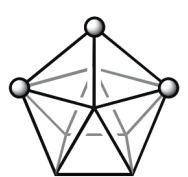

$9_{2}$

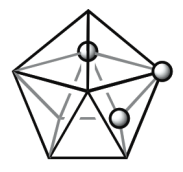

$9_{9}$

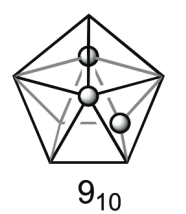

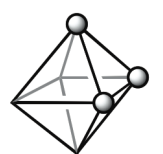

61

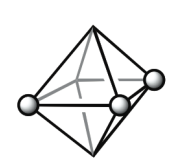

$6_{2}$

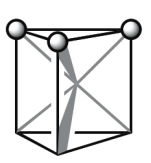

$6_{3}$

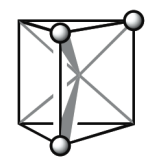

64

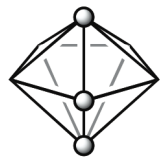

$7_{1}$

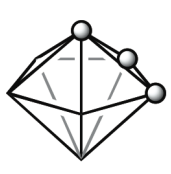

$7_{2}$
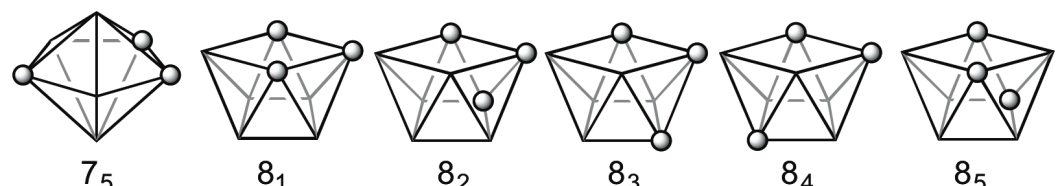

81

$8_{3}$

$8_{4}$
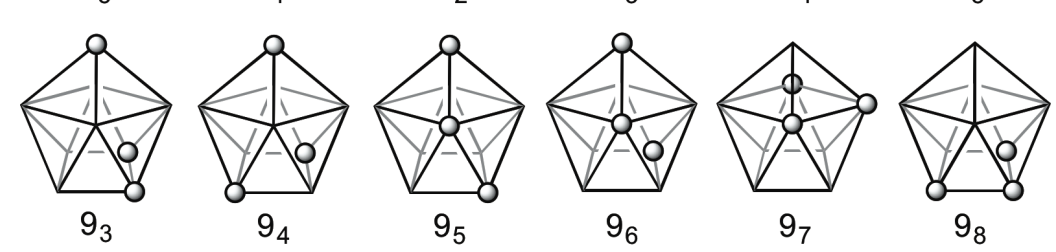

$9_{7}$

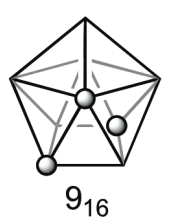

Figure 5: (above) Histogram for all the $\left[\mathrm{Dy}(\mathrm{OH})_{3}\left(\mathrm{H}_{2} \mathrm{O}\right)_{\mathrm{n}-3}\right]$ complexes (for coordination number equal to 2 the $\left[\mathrm{Dy}(\mathrm{OH})_{2}\right]^{+}$complexes were considered) showing their calculated $g_{z}$ value (black points) at CASSCF+RASSI level; the systems are labeled as $n_{x}$ where $n$ is the coordination number. The horizontal lines correspond to the Kramers doublet energies under the level involved in the spin relaxation mechanism (as criterion, a matrix element of the transition magnetic moment above 0.1 was considered). The color of the highest level indicates the main mechanism of the spin relaxation: red indicates quantum tunneling or thermally-assisted quantum tunneling, blue to a Orbach mechanism while violet represents a mixture of Orbach and tunneling mechanisms. (below) Structural description of the Dy ${ }^{\mathrm{III}}$ complexes; the circles correspond to the $\mathrm{OH}^{-}$ligands. 
From the histogram of Fig. 5 we can extract certain conclusions: (i) Most of the structures are highly axial; in only two cases, the $g_{z}$ value is below 14 with easy plane behavior (complexes $3_{1}$ and $6_{1}$, these two complexes have a three-fold symmetry axis, this symmetry axis is also present in one additional structure $6_{3}$ with a $g_{z}$ value close to 17 ) and seven complexes are in the interval between 14 and $18\left(4_{2}, 5_{4}, 6_{3}, 7_{2}, 8_{2}, 9_{2}\right.$ and $\left.9_{9}\right)$, all these complexes have a coordination polyhedron with the three hydroxo groups in a triangular phase, with the sole exception of the $9_{2}$ system). These results show that the presence of three-fold symmetry axis reduces the axiality in agreement with the easy plane behavior found in one Dy ${ }^{\mathrm{III}}$ complex with coordination number 7 reported by Sessoli and Costes. (ii) In all these nine systems with relative low $g_{z}$ values, the spin relaxation mechanism is due to quantum tunneling in the ground state. The spin relaxation mechanism[78] is mainly due to quantum tunneling or thermally-assisted quantum tunneling (red levels in Fig. 5) especially in low coordination number complexes. For higher coordination numbers both mechanisms and also a mixture of Orbach and quantum tunneling mechanisms are usual (violet levels). Only one case $5_{5}$ shows only Orbach mechanism for the spin relaxation. (iii) The highest spin relaxation barriers correspond to the lowest coordination number 2 which also shows the highest axiality with $\mathrm{g}_{\mathrm{z}}$ values around 19.9. This appealing feature of the Dy ${ }^{\text {III }}$ complexes with very low coordination numbers was already noted by other authors, in systems with coordination $1,[121] 2,[122]$ and 3.[123]

Figure 6 describes the spin relaxation mechanism of the magnetization obtained from the matrix elements of the transition magnetic moments corresponding to the calculated Kramers doublets at CASSCF+RASSI level.[78] For the linear $\left[\mathrm{Dy}(\mathrm{OH})_{2}\right]^{+}$complex, the quantum tunneling (red arrows) in the ground state is weak (ca. $2.810^{-9}$ ) and with the criterion used to build the histogram of Figure 5 (matrix element of the transition magnetic moment above 0.1 ) the relaxation will occur through the fourth excited state, giving a barrier close to $2500 \mathrm{~cm}^{-1}$. Moreover, the Orbach processes (blue arrows) have similar probabilities as those involving thermally-assisted quantum 
tunneling approach. In order to have a neutral Dy ${ }^{\mathrm{III}}$ complex showing linear coordination, we also considered the case with one hydroxo and one oxo ligand (see Figure 6). For this [Dy(OH)O] system the spin relaxation is similar to the equivalent homoleptic hydroxo complex; however, the relaxation mechanism involves the fifth excited state, again with the thermally-assisted quantum tunneling approach, resulting in a higher energy barrier above $3000 \mathrm{~cm}^{-1}$.
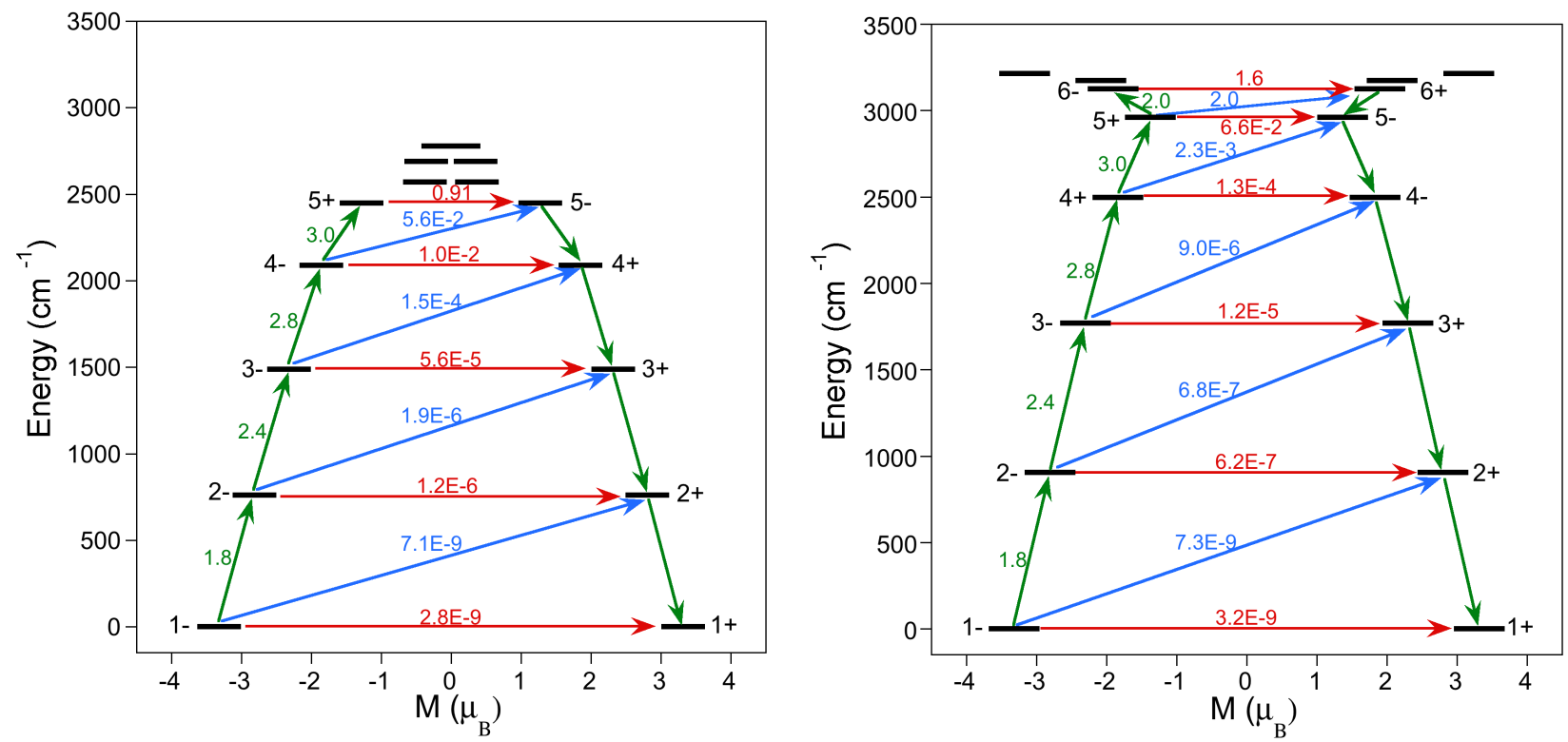

Figure 6: Magnetization blocking barrier at CASSCF+RASSI level calculated for the $\left[\mathrm{Dy}(\mathrm{OH})_{2}\right]^{+}$ (left) and $[\mathrm{Dy}(\mathrm{OH}) \mathrm{O}]$ (right) linear complexes. The black lines correspond to the Kramers doublet as a function of the magnetic moment. Red, blue and green lines correspond to quantum tunneling (and thermally-assisted quantum tunneling), Orbach and magnetization reversal mechanism (thermal crossing) respectively. The values indicated close to the arrows indicate the matrix elements of the transition magnetic moments.

\section{Concluding Remarks}

Magnetic anisotropy is probably the key property for improving the physical properties of singlemolecule magnets in order to attain higher blocking temperatures and consequently to envisage some possible new applications. For lanthanide systems, life is easy, because intrinsically they have large spin-orbit coupling which is the source of the magnetic anisotropy. However, in transition metal complexes, the metal must show a particular combination of electronic configuration and 
coordination mode to achieve large magnetic anisotropies. From the theoretical point of view, CASSCF or CASPT2 (NEVPT2) methods including spin-orbit effects give a quantitative tool to determine the zero-field splitting parameters, D and E, with reasonable accuracy for either lanthanides or transition metal complexes.

In order to predict and also to understand the origin of large magnetic anisotropy in transition metal complexes, we developed a simple model based on the qualitative estimation of the energy splitting of the $\mathrm{d}$ orbitals. This model correctly predicts the magnetic properties of all the mononuclear transition metal complexes reported (more than thirty compounds) with only two exceptions: (i) a highly symmetric Co ${ }^{\text {II }}$ complex. In this case, the main Slater determinant should give a positive D value; however, the sum of all the contributions was negative. (ii) a linear $\mathrm{Fe}^{\mathrm{I}}$ complex with the most stable $\mathrm{d}$ orbital is $\mathrm{d}_{\mathrm{z}^{2}}$ (with this orbital oriented towards the two ligands) that cannot be reproduced by the simple extended-Hückel calculations.

The use of an orbital-based model to explain magnetic anisotropy in lanthanide systems is generally not convenient, due to the large spin-orbit contributions. However, anisotropy can be analyzed in terms of the electron density and the electrostatic potential. Lanthanide and transition metal complexes showing large axial anisotropy share a common feature: they must have a small first excitation energy at CASSCF level (spin-free without spin-orbit effects). In the lanthanide systems, as we have discussed in detail with regard to Dy ${ }^{\mathrm{III}}$ complexes, the oblate/prolate shape of the electron density is crucial for anisotropy. The presence of a spin-free first excited state with a similar shape of the electron density as in the ground state will lead to a spin-orbit ground state with high anisotropy if higher excited states make a low contribution (a large second excitation energy). The spatial distribution of this electron density is also influenced by the electrostatic potential caused by the ligands to reduce the electronic repulsion. Thus, the electron cloud of the metal tries to be accommodated in the low electrostatic regions, avoiding the charged ligand or ligands with the shortest metal-ligand distances. In most cases this allows prediction of the position of the electron density with these two simple criteria (ligand charges and M-L distances) and consequently the 
direction of the magnetic moment of the mononuclear lanthanide complex. This analysis can be extended to all the paramagnetic centers of a polynuclear complex and provides very useful information about the relative orientation of the local magnetic moments. Finally, by screening of several coordination modes of $\mathrm{Dy}^{\mathrm{III}}$ complexes, we can conclude from the CASSCF+RASSI calculations that the highest spin relaxation barriers and also the highest axiality are found in the lowest coordination number systems.

\section{Acknowledgements}

The research reported here was supported by the Spanish Ministerio de Economía y Competitividad (grants CTQ2011-23862-C02-01) and the regional Generalitat de Catalunya authority (2009SGR1459). S.G.C. thanks the Spanish Ministerio de Educación, Cultura y Deporte for a predoctoral fellowship. D.A. thanks to Conicyt-Chile for a predoctoral fellowship. The authors thankfully acknowledge the computer resources, technical expertise and assistance provided by the CESCA.

\section{References}

[1] R. Skomski, Simple Models of Magnetism, Oxford University Press, Oxford, 2008.

[2] D. Gatteschi, R. Sessoli, Angew. Chem. Int. Ed., 42 (2003) 268-297.

[3] D. Gatteschi, R. Sessoli, J. Villain, Molecular Nanomagnets, Oxford University Press, Oxford, 2006.

[4] J.R. Friedman, M.P. Sarachik, Annu. Rev. Condens. Matter Phys., 1 (2010) 109-128.

[5] G. Aromi, E.K. Brechin, Synthesis of 3d metallic single-molecule magnets, in: R. Winpenny (Ed.) Single-Molecule Magnets and Related Phenomena, 2006, pp. 1-67.

[6] G. Aromí, E.J.L. McInnes, R.E.P. Winpenny, Recent Synthetic Results Involving Single Molecule Magnets, in: R. Winpenny (Ed.) Molecular Cluster Magnets, World Scientific, Singapore, 2012.

[7] R. Boca, Theoretical Foundations of Molecular Magnetism, Elsevier, Lausanne, 1999.

[8] R. Boca, Coord. Chem. Rev., 248 (2004) 757-815.

[9] R. Sessoli, D. Gatteschi, A. Caneshi, M.A. Novak, Nature, 365 (1993) 141-143.

[10] C.J. Milios, R. Inglis, A. Vinslava, R. Bagai, W. Wernsdorfer, S. Parsons, S.P. Perlepes, G. Christou, E.K. Brechin, J. Am. Chem. Soc., 129 (2007) 12505-12511.

[11] C.J. Milios, A. Vinslava, W. Wernsdorfer, S. Moggach, S. Parsons, S.P. Perlepes, G. Christou, E.K. Brechin, J. Am. Chem. Soc., 129 (2007) 2754-2755.

[12] E. Cremades, J. Cano, E. Ruiz, G. Rajaraman, C.J. Milios, E.K. Brechin, Inorg. Chem., 48 (2009) 8012-8019.

[13] R. Inglis, C.J. Milios, L.F. Jones, S. Piligkos, E.K. Brechin, Chem. Commun., 48 (2012) 181190.

[14] R. Bagai, W. Wernsdorfer, K.A. Abboud, G. Christou, J. Am. Chem. Soc., 129 (2007) 1291812919. 
[15] A. Abragam, B. Bleaney, Electron Paramagnetic Resonance of Transition Ions, Dover, New York, 1970.

[16] R.J. Blagg, L. Ungur, F. Tuna, J. Speak, P. Comar, D. Collison, W. Wernsdorfer, E.J.L. McInnes, L.F. Chibotaru, R.E.P. Winpenny, Nat. Chem., 5 (2013) 673-678.

[17] N. Ishikawa, M. Sugita, T. Ishikawa, S. Koshihara, Y. Kaizu, J. Am. Chem. Soc., 125 (2003) 8694-8695.

[18] P. Zhang, Y.N. Guo, J.K. Tang, Coord. Chem. Rev., 257 (2013) 1728-1763.

[19] R.A. Layfield, Organometallics, 33 (2014) 1084-1099.

[20] M.A. Antunes, L.C.J. Pereira, I.C. Santos, M. Mazzanti, J. Marcalo, M. Almeida, Inorg. Chem., 50 (2011) 9915-9917.

[21] J.J. Baldovi, S. Cardona-Serra, J.M. Clemente-Juan, E. Coronado, A. Gaita-Arino, Chem. Sci., 4 (2013) 938-946.

[22] K.R. Meihaus, J.D. Rinehart, J.R. Long, Inorg. Chem., 50 (2011) 8484-8489.

[23] J.D. Rinehart, J.R. Long, J. Am. Chem. Soc., 131 (2009) 12558-12559.

[24] J.T. Coutinho, M.A. Antunes, L.C.J. Pereira, H. Bolvin, J. Marcalo, M. Mazzanti, M. Almeida, Dalton Trans., 41 (2012) 13568-13571.

[25] F. Moro, D.P. Mills, S.T. Liddle, J. van Slageren, Angew. Chem. Int. Ed., 52 (2013) 34303433.

[26] D.M. King, F. Tuna, J. McMaster, W. Lewis, A.J. Blake, E.J.L. McInnes, S.T. Liddle, Angew. Chem. Int. Ed., 52 (2013) 4921-4924.

[27] N. Magnani, C. Apostolidis, A. Morgenstern, E. Colineau, J.-C. Griveau, H. Bolvin, O. Walter, R. Caciuffo, Angew. Chem. Int. Ed., 50 (2011) 1696-1698.

[28] D.N. Woodruff, R.E.P. Winpenny, R.A. Layfield, Chem. Rev., 113 (2013) 5110-5148.

[29] H.L.C. Feltham, S. Brooker, Coord. Chem. Rev., 276 (2014) 1-33.

[30] D.E. Freedman, W.H. Harman, T.D. Harris, G.J. Long, C.J. Chang, J.R. Long, J. Am. Chem. Soc., 132 (2010) 1224-1225.

[31] W.H. Harman, T.D. Harris, D.E. Freedman, H. Fong, A. Chang, J.D. Rinehart, A. Ozarowski, M.T. Sougrati, F. Grandjean, G.J. Long, J.R. Long, C.J. Chang, J. Am. Chem. Soc., 132 (2010) $18115-18126$.

[32] S. Gómez-Coca, E. Cremades, N. Aliaga-Alcalde, E. Ruiz, J. Am. Chem. Soc., 135 (2013) 7010-7018.

[33] R. Ishikawa, R. Miyamoto, H. Nojiri, B.K. Breedlove, M. Yamashita, Inorg. Chem., 52 (2013) 8300-8302.

[34] J. Vallejo, A. Pascual-Álvarez, J. Cano, I. Castro, M. Julve, F. Lloret, J. Krzystek, G. De Munno, D. Armentano, W. Wernsdorfer, R. Ruiz-García, E. Pardo, Angew. Chem. Int. Ed., 52 (2013) 14075-14079.

[35] R.C. Poulten, M.J. Page, A.G. Algarra, J.J. Le Roy, I. López, E. Carter, A. Llobet, S.A. Macgregor, M.F. Mahon, D.M. Murphy, M. Murugesu, M.K. Whittlesey, J. Am. Chem. Soc., 135 (2013) 13640-13643.

[36] J. Martínez-Lillo, T.F. Mastropietro, E. Lhotel, C. Paulsen, J. Cano, G. De Munno, J. Faus, F. Lloret, M. Julve, S. Nellutla, J. Krzystek, J. Am. Chem. Soc., 135 (2013) 13737-13748.

[37] J. Cirera, E. Ruiz, S. Alvarez, Inorg. Chem., 47 (2008) 2871-2889.

[38] S. Gomez-Coca, E. Cremades, N. Aliaga-Alcalde, E. Ruiz, Inorg. Chem., 53 (2014) 676-678.

[39] R. Ruamps, L.J. Batchelor, R. Maurice, N. Gogoi, P. Jimenez-Lozano, N. Guihery, C. de Graaf, A.L. Barra, J.P. Sutter, T. Mallah, Chem. Eur. J., 19 (2013) 950-956.

[40] D. Weismann, Y. Sun, Y. Lan, G. Wolmershaeuser, A.K. Powell, H. Sitzmann, Chem. Eur. J., 17 (2011) 4700-4704.

[41] P.-H. Lin, N.C. Smythe, S.I. Gorelsky, S. Maguire, N.J. Henson, I. Korobkov, B.L. Scott, J.C. Gordon, R.T. Baker, M. Murugesu, J. Am. Chem. Soc., 133 (2011) 15806-15809.

[42] A. Eichhöfer, Y. Lan, V. Mereacre, T. Bodenstein, F. Weigend, Inorg. Chem., 53 (2014) 19621974. 
[43] S. Mossin, B.L. Tran, D. Adhikari, M. Pink, F.W. Heinemann, J. Sutter, R.K. Szilagyi, K. Meyer, D.J. Mindiola, J. Am. Chem. Soc., 134 (2012) 13651-13661.

[44] J.M. Zadrozny, M. Atanasov, A.M. Bryan, C.-Y. Lin, B.D. Rekken, P.P. Power, F. Neese, J.R. Long, Chem. Sci., 4 (2013) 125-138.

[45] J.M. Zadrozny, D.J. Xiao, M. Atanasov, G.J. Long, F. Grandjean, F. Neese, J.R. Long, Nat Chem, 5 (2013) 577-581.

[46] X. Feng, C. Mathonière, I.-R. Jeon, M. Rouzières, A. Ozarowski, M.L. Aubrey, M.I. Gonzalez, R. Clérac, J.R. Long, J. Am. Chem. Soc., 135 (2013) 15880-15884.

[47] C. Mathonière, H.-J. Lin, D. Siretanu, R. Clérac, J.M. Smith, J. Am. Chem. Soc., 135 (2013) 19083-19086.

[48] P.P. Samuel, K.C. Mondal, N. Amin Sk, H.W. Roesky, E. Carl, R. Neufeld, D. Stalke, S. Demeshko, F. Meyer, L. Ungur, L.F. Chibotaru, J. Christian, V. Ramachandran, J. van Tol, N.S. Dalal, J. Am. Chem. Soc., 136 (2014) 11964-11971.

[49] T. Jurca, A. Farghal, P.-H. Lin, I. Korobkov, M. Murugesu, D.S. Richeson, J. Am. Chem. Soc., 133 (2011) 15814-15817.

[50] J.M. Zadrozny, J.R. Long, J. Am. Chem. Soc., 133 (2011) 20732-20734.

[51] J.M. Zadrozny, J. Telser, J.R. Long, Polyhedron, 64 (2013) 209-217.

[52] A. Buchholz, A.O. Eseola, W. Plass, C. R. Chim., 15 (2012) 929-936.

[53] Y.-Y. Zhu, C. Cui, Y.-Q. Zhang, J.-H. Jia, X. Guo, C. Gao, K. Qian, S.-D. Jiang, B.-W. Wang, Z.-M. Wang, S. Gao, Chem. Sci., 4 (2013) 1802-1806.

[54] V. Chandrasekhar, A. Dey, A.J. Mota, E. Colacio, Inorg. Chem., 52 (2013) 4554-4561.

[55] F. Yang, Q. Zhou, Y. Zhang, G. Zeng, G. Li, Z. Shi, B. Wang, S. Feng, Chem. Commun., 49 (2013) 5289-5291.

[56] D.-K. Cao, J.-Q. Feng, M. Ren, Y.-W. Gu, Y. Song, M.D. Ward, Chem. Commun., 49 (2013) 8863-8865.

[57] F. Habib, O.R. Luca, V. Vieru, M. Shiddiq, I. Korobkov, S.I. Gorelsky, M.K. Takase, L.F. Chibotaru, S. Hill, R.H. Crabtree, M. Murugesu, Angew. Chem. Int. Ed., 52 (2013) 1129011293.

[58] R. Boca, J. Miklovic, J. Titis, Inorg. Chem., 53 (2014) 2367-2369.

[59] R. Ruamps, L.J. Batchelor, R. Guillot, G. Zakhia, A.-L. Barra, W. Wernsdorfer, N. Guihery, T. Mallah, Chem. Sci., 5 (2014) 3418-3424.

[60] D.M. Piñero Cruz, D.N. Woodruff, I.-R. Jeon, I. Bhowmick, M. Secu, E.A. Hillard, P. Dechambenoit, R. Clerac, New J. Chem., 38 (2014) 3443-3448.

[61] L. Chen, J. Wang, J.-M. Wei, W. Wernsdorfer, X.-T. Chen, Y.-Q. Zhang, Y. Song, Z.-L. Xue, J. Am. Chem. Soc., 136 (2014) 12213-12216.

[62] M.R. Saber, K.R. Dunbar, Chem. Commun., 50 (2014) 12266-12269.

[63] M.S. Fataftah, J.M. Zadrozny, D.M. Rogers, D.E. Freedman, Inorg. Chem., 53 (2014) 1071610721.

[64] S. Vaidya, A. Upadhyay, S.K. Singh, T. Gupta, S. Tewary, S.K. Langley, J.P.S. Walsh, K.S. Murray, G. Rajaraman, M. Shanmugam, Chem. Commun., (2015) DOI: 10.1039/C1034CC08305A.

[65] A. Cornia, L. Rigamonti, S. Boccedi, R. Clerac, M. Rouzieres, L. Sorace, Chem. Commun., 50 (2014) 15191-15194.

[66] J.M. Zadrozny, J. Liu, N.A. Piro, C.J. Chang, S. Hill, J.R. Long, Chem. Commun., 48 (2012) 3927-3929.

[67] A. Jesche, R.W. McCallum, S. Thimmaiah, J.L. Jacobs, V. Taufour, A. Kreyssig, R.S. Houk, S.L. Bud'ko, P.C. Canfield, Nat. Commun., 5 (2014) 3333.

[68] E. Lucaccini, L. Sorace, M. Perfetti, J.P. Costes, R. Sessoli, Chem. Commun., 50 (2014) 16481651.

[69] J. Vallejo, I. Castro, R. Ruiz-Garcia, J. Cano, M. Julve, F. Lloret, G. De Munno, W. Wernsdorfer, E. Pardo, J. Am. Chem. Soc., 134 (2012) 15704-15707. 
[70] E. Colacio, J. Ruiz, E. Ruiz, E. Cremades, J. Krzystek, S. Carretta, J. Cano, T. Guidi, W. Wernsdorfer, E.K. Brechin, Angew. Chem. Int. Ed., 52 (2013) 9130-9134.

[71] W. Huang, T. Liu, D. Wu, J. Cheng, Z.W. Ouyang, C. Duan, Dalton Trans., 42 (2013) 1532615331.

[72] D. Wu, X. Zhang, P. Huang, W. Huang, M. Ruan, Z.W. Ouyang, Inorg. Chem., 52 (2013) 10976-10982.

[73] R. Herchel, L. Váhovská, I. Potocnák, Z. Trávnícek, Inorg. Chem., 53 (2014) 5896-5898.

[74] S. Gomez-Coca, A. Urtizbarea, E. Cremades, P.J. Alonso, A. Camón, E. Ruiz, F. Luis, Nat. Commun., 5 (2014) 4300.

[75] X.-C. Huang, C. Zhou, D. Shao, X.-Y. Wang, Inorg. Chem., 53 (2014) 12671-12673.

[76] E. Ruiz, J. Cirera, J. Cano, S. Alvarez, C. Loose, J. Kortus, Chem. Commun., (2008) 52-54.

[77] O. Waldmann, Inorg. Chem., 46 (2007) 10035-10037.

[78] L.F. Chibotaru, L. Ungur, J. Chem. Phys., 137 (2012) 064112.

[79] S.Y. Lin, W. Wernsdorfer, L. Ungur, A.K. Powell, Y.N. Guo, J.K. Tang, L. Zhao, L.F. Chibotaru, H.J. Zhang, Angew. Chem. Int. Ed., 51 (2012) 12767-12771.

[80] J. Kortus, M.R. Pederson, T. Baruah, N. Bernstein, C.S. Hellberg, Polyhedron, 22 (2003) 18711876.

[81] F. Neese, J. Chem. Phys, 127 (2007) 164112.

[82] F. Neese, E.I. Solomon, Interpretation and Calculation of Spin-Hamiltonian Parameters in Transition Metal Complexes, in: J.S. Miller, M. Drillon (Eds.) Magnetism: Molecules to Materials, Wiley-VCH, Weinheim, 2003, pp. 345.

[83] R. Maurice, R. Bastardis, C. de Graaf, N. Suaud, T. Mallah, N. Guihery, J. Chem. Theory Comput., 5 (2009) 2977-2984.

[84] R. Maurice, N. Guihery, R. Bastardis, C. de Graaf, J. Chem. Theory Comput., 6 (2010) 55-65.

[85] E. Cremades, E. Ruiz, Inorg. Chem., 50 (2011) 4016-4020.

[86] M. Atanasov, D. Ganyushin, D.A. Pantazis, K. Sivalingam, F. Neese, Inorg. Chem., 50 (2011) $7460-7477$.

[87] M. Atanasov, J.M. Zadrozny, J.R. Long, F. Neese, Chem. Sci., 4 (2013) 139-156.

[88] J.D. Rinehart, J.R. Long, Chem. Sci., 2 (2011) 2078-2085.

[89] N.F. Chilton, S.K. Langley, B. Moubaraki, A. Soncini, S.R. Batten, K.S. Murray, Chem. Sci., 4 (2013) 1719-1730.

[90] J.J. Baldovi, J.J. Borras-Almenar, J.M. Clemente-Juan, E. Coronado, A. Gaita-Arino, Dalton Trans., 41 (2012) 13705-13710.

[91] J.J. Baldovi, S. Cardona-Serra, J.M. Clemente-Juan, E. Coronado, A. Gaita-Arino, A. Palii, Inorg. Chem., 51 (2012) 12565-12574.

[92] M.-E. Boulon, G. Cucinotta, J. Luzon, C. Degl'Innocenti, M. Perfetti, K. Bernot, G. Calvez, A. Caneschi, R. Sessoli, Angew. Chem. Int. Ed., 52 (2013) 350-354.

[93] G. Cucinotta, M. Perfetti, J. Luzon, M. Etienne, P.-E. Car, A. Caneschi, G. Calvez, K. Bernot, R. Sessoli, Angew. Chem. Int. Ed., 51 (2012) 1606-1610.

[94] J. Luzon, R. Sessoli, Dalton Trans., 41 (2012) 13556.

[95] D. Aravena, E. Ruiz, Inorg. Chem., 52 (2013) 13770-13778.

[96] G.-J. Chen, Y.-N. Guo, J.-L. Tian, J. Tang, W. Gu, X. Liu, S.-P. Yan, P. Cheng, D.-Z. Liao, Chem. Eur. J., 18 (2012) 2484-2487.

[97] S.-D. Jiang, B.-W. Wang, G. Su, Z.-M. Wang, S. Gao, Angew. Chem. Int. Ed., 49 (2010) $7448-7451$.

[98] G.-J. Chen, C.-Y. Gao, J.-L. Tian, J. Tang, W. Gu, X. Liu, S.-P. Yan, D.-Z. Liao, P. Cheng, Dalton Trans., 40 (2011) 5579-5583.

[99] H. Wang, K. Wang, J. Tao, J. Jiang, Chem. Commun., 48 (2012) 2973-2975.

[100] Y. Bi, Y.-N. Guo, L. Zhao, Y. Guo, S.-Y. Lin, S.-D. Jiang, J. Tang, B.-W. Wang, S. Gao, Chem. Eur. J., 17 (2011) 12476-12481.

[101] D.-P. Li, T.-W. Wang, C.-H. Li, D.-S. Liu, Y.-Z. Li, X.-Z. You, Chem. Commun., 46 (2010) 2929-2931. 
[102] M. Jeletic, P.-H. Lin, J.J. Le Roy, I. Korobkov, S.I. Gorelsky, M. Murugesu, J. Am. Chem. Soc., 133 (2011) 19286-19289.

[103] L. Ungur, J.J. Le Roy, I. Korobkov, M. Murugesu, L.F. Chibotaru, Angew. Chem. Int. Ed., 53 (2014) 4413-4417.

[104] J.-L. Liu, Y.-C. Chen, Y.-Z. Zheng, W.-Q. Lin, L. Ungur, W. Wernsdorfer, L.F. Chibotaru, M.-L. Tong, Chem. Sci., 4 (2013) 3310-3316.

[105] J.J. Le Roy, M. Jeletic, S.I. Gorelsky, I. Korobkov, L. Ungur, L.F. Chibotaru, M. Murugesu, J. Am. Chem. Soc., 135 (2013) 3502-3510.

[106] T.T. da Cunha, J. Jung, M.-E. Boulon, G. Campo, F. Pointillart, C.L.M. Pereira, B. Le Guennic, O. Cador, K. Bernot, F. Pineider, S.p. Golhen, L.n. Ouahab, J. Am. Chem. Soc., 135 (2013) 16332-16335.

[107] M. Menelaou, F. Ouharrou, L. Rodríguez, O. Roubeau, S.J. Teat, N. Aliaga-Alcalde, Chem. Eur. J., 18 (2012) 11545-11549.

[108] D.-P. Li, X.-P. Zhang, T.-W. Wang, B.-B. Ma, C.-H. Li, Y.-Z. Li, X.-Z. You, Chem. Commun., 47 (2011) 6867-6869.

[109] J. Ruiz, A.J. Mota, A. Rodriguez-Dieguez, S. Titos, J.M. Herrera, E. Ruiz, E. Cremades, J.P. Costes, E. Colacio, Chem. Commun., 48 (2012) 7916-7918.

[110] U.J. Williams, B.D. Mahoney, P.T. DeGregorio, P.J. Carroll, E. Nakamaru-Ogiso, J.M. Kikkawa, E.J. Schelter, Chem. Commun., 48 (2012) 5593-5595.

[111] Y. Wang, X.-L. Li, T.-W. Wang, Y. Song, X.-Z. You, Inorg. Chem., 49 (2010) 969-976.

[112] A. Bhunia, M.T. Gamer, L. Ungur, L.F. Chibotaru, A.K. Powell, Y. Lan, P.W. Roesky, F. Menges, C. Riehn, G. Niedner-Schatteburg, Inorg. Chem., 51 (2012) 9589-9597.

[113] S.N. Konig, N.F. Chilton, C. Maichle-Mossmer, E.M. Pineda, T. Pugh, R. Anwander, R.A. Layfield, Dalton Trans., 43 (2014) 3035-3038.

[114] F. Pointillart, Y. Le Gal, S. Golhen, O. Cador, L. Ouahab, Chem. Eur. J., 17 (2011) 1039710404.

[115] J.-L. Liu, K. Yuan, J.-D. Leng, L. Ungur, W. Wernsdorfer, F.-S. Guo, L.F. Chibotaru, M.-L. Tong, Inorg. Chem., 51 (2012) 8538-8544.

[116] H.L.C. Feltham, Y. Lan, F. Kloewer, L. Ungur, L.F. Chibotaru, A.K. Powell, S. Brooker, Chem. Eur. J., 17 (2011) 4362-4365.

[117] N.F. Chilton, D. Collison, E.J.L. McInnes, R.E.P. Winpenny, A. Soncini, Nat. Commun., 4 (2013) 2551.

[118] F. Aquilante, L. De Vico, N. Ferre, G. Ghigo, P.A. Malmqvist, P. Neogrady, T.B. Pedersen, M. Pitonak, M. Reiher, B.O. Roos, L. Serrano-Andres, M. Urban, V. Veryazov, R. Lindh, J. Comput. Chem., 31 (2010) 224-247.

[119] The position of the $\mathrm{H}$ atoms was selected in order to simulate bulkier ligands. Thus, the $\mathrm{H}$ atoms of the $\mathrm{OH}$ ligands were placed on the plane formed by the Dy-O bond and $\mathrm{z}$ axis. The two $\mathrm{H}$ atoms of the water ligands are also placed by considering the mentioned plane. Thus, a oxygen lone pair is aligned with this plane and the two $\mathrm{H}$ atoms in the other "tetrahedral" positions. Hence, the repulsion between the oxygen susbtituents should be minimized. Also, as criterion the maximum symmetry in the molecule was keeped by placing the equivalent hydrogen atoms in the appropriate positions. We employed the follwing structural parameters: distances Dy-OX = 2.25 $\AA$; O-H = $0.96 \AA$; Dy-O (in $[\mathrm{Dy}(\mathrm{OH}) \mathrm{O}])=2.10 \AA$; angles Dy-O-H = $109.47^{\circ} ; \mathrm{H}-\mathrm{O}-\mathrm{H}=104.5^{\circ}$; O-Dy-O (in 22 ) : $135^{\circ}$.

[120] F.H. Allen, Acta Crystallogr. Sect. B: Struct. Sci., 58 (2002) 380-388.

[121] L. Ungur, L.F. Chibotaru, Phys. Chem. Chem. Phys., 13 (2011) 20086-20090.

[122] N.F. Chilton, C.A.P. Goodwin, D.P. Mills, R.E.P. Winpenny, Chem. Commun., 51 (2015) 101-103.

[123] S.K. Singh, T. Gupta, M. Shanmugam, G. Rajaraman, Chem. Commun., 50 (2014) 1551315516. 